\title{
Porosity Development and Reactivity Changes of Coal-Biomass Blends During Co- Pyrolysis at Various Temperatures
}

Ami Vyas ${ }^{1}$, Thiago Chellappa ${ }^{2,3}$, Jillian L. Goldfarb ${ }^{2,4 *}$

1. Department of Electrical and Computer Engineering, Boston University, 8 St. Mary's Street, Boston MA 02215, USA

2. Department of Mechanical Engineering, Boston University, 110 Cummington Mall, Boston MA 02215, USA

3. Federal University of Rio Grande do Norte, Department of Mechanical Engineering and Department of Arts, 59078-970, Natal/RN, Brazil

4. Division of Materials Science \& Engineering, Boston University, 15 St. Mary's Street, Brookline, MA 02446, USA

\begin{abstract}
While co-firing of coal and biomass represents an inexpensive, efficient, short-range future method to incorporate more renewable fuels into our energy generation portfolio, we know little about how U.S. domestic coals and biomasses behave together. Computational fluid dynamics models are routinely used to model combustion of solids in packed and fluidized beds, for which porosity changes are a key variable to predicting heterogeneities in transport and fuel reactivity. This work probes the changes in carbon contents, thermal reactivities, surface areas, and porosities as a function of blend ratio and pyrolysis temperature for a series of Pennsylvania coal and feed corn stover biomass blends. There is a fairly linear trend between both percent biomass in a blend and pyrolysis temperature with volatile matter content of the char; this additive nature of the blended streams does not extend to surface area and porosity. Surface areas (measured by $\mathrm{N}_{2}$ adsorption isotherms) peaked for the pure coal and $10 \mathrm{wt} \%$ biomass peaks around $600^{\circ} \mathrm{C}$, and for the 20 and $50 \mathrm{wt} \%$ biomass and pure biomass between 600 and $750^{\circ} \mathrm{C}$. The surface area decreases for all samples when the pyrolysis temperature reaches $900^{\circ} \mathrm{C}$. Generally, higher temperatures led to enhanced microporosity across all fuels and blends, though this was not a linear trend. Of keen interest to co-firing scenarios was the disappearance of segregated oxidation behavior of the coal-biomass blends at pyrolysis temperatures as low as $300^{\circ} \mathrm{C}$, suggesting that co-firing could be improved by preheating the comingled fuels and low temperatures before their introduction into the boiler.
\end{abstract}

\section{Keywords}

Coal; Biomass; Co-pyrolysis; Porosity; Surface Area; Thermal Reactivity

\footnotetext{
* To whom correspondence should be addressed: jilliang@bu.edu, JillianLGoldfarb@ gmail.com; (617) 3533883
} 


\section{Introduction}

Second-generation biomass feedstocks, comprised of agricultural waste and organic byproducts, represent a possible stopgap source replacement for dwindling conventional fossil fuel sources. They may be blended with traditional fuels such as coal, an avenue for immediate usage given the infrastructure already in place for coal, or treated separately to produce $100 \%$ renewable energy, a promise for the more distant future. The co-firing of biomass and coal is an efficient and inexpensive use of biomass that reduces net $\mathrm{CO}_{2}$ emissions from power plants [1]. Biomasses are often used to achieve a better control of the burning process; in co-combustion they increase the volatile matter content, flame stability, and alter $\mathrm{NO}_{\mathrm{x}}$ precursor formation [2-4]. Despite these applicable benefits to the United States, the majority of studies on coal-biomass pyrolysis and combustion behavior originate in Europe and Asia. While the overall trends that our worldwide counterparts have found are reasonably applicable to our energy generation systems, we use different coals and produce different agricultural waste streams, leading to differences in co-firing efficiencies. Coal-biomass systems from the Northeastern/Mid-Atlantic regions of the U.S. tend to use coals of higher sulfur content and different biomasses than many previous studies. Because the chemical characteristics of the blend dictates its thermal and kinetics profile, without data on relevant systems, it is difficult to design processes to utilize locally available biomass and East Coast coal. The ability to co-fire coal and biomass depends on the characteristics of the power plant, availability and price of biomass within a reasonable transportable distance of the plant, and the perceived economic value of environmental benefits [5].

Biomass and coal are carbonaceous fuels that progress from pyrolysis to oxidation through a series of steps, for which solid devolatilization is the first step [6,7]. Due to its less-condensed aromatic nature, biomass pyrolysis yields different temperature profiles than those of coal decomposition, yet their separate devolatilization stages can often be followed in a co-pyrolysis scenario [8]. In order to design an effective thermochemical conversion unit, we must know the chemical composition, thermal behavior, and reactivity of the fuel in question [9]. As Gayan et al. [10] note, combustion models used for coal must be modified to include biomass' higher reactivity and volatile matter content than coal. During devolatilization, the solid's macromolecular structure changes due to depolymerization, vaporization, and cross-linking of 
the solid matrix, causing aromatic ring rupture, evolving gases and tars, and forming a carbonaceous char. Devolatilization is often modeled using different rate expressions for each conversion (gas, tar, and char) process [11]. However, there is considerable debate as to whether or not devolatilization of fuel blends can be modeled as an additive function of each fuel's contribution [12-14].

To improve the combustion efficiency and reduce pollutant emissions of solid biomass and blended biomass-coal streams, we need a better understanding of the conversion processes. Computational fluid dynamics (CFD) simulations are commonly used to model the combustion of solid fuels in packed and fluidized beds [15-21]. However, models that neglect changes in porosity are unable to account for heterogeneities in transport and fuel consumption [22], as changes in char reactivity can mediate carbon burnout [23]. The surface area and porosity of chars are one of many determining factors in whether reaction rates - be it pyrolysis, oxidation, adsorption, chemical, etc. - in CFD models are controlled by gaseous diffusion through the pore surface, versus kinetically controlled regimes where reaction rates are limited by total internal surface area [24-27]. Often, such intrinsic solid reactivities are expressed on a basis of available surface area [28]. In such models, Knudsen diffusion is often neglected, assumed to be inconsequential as compared to molecular diffusion [29]. To improve the accuracy of CFD models, the changing volatile fraction and porosity of solid fuels can be incorporated [30-32]. As pyrolysis continues, the solid fraction of a combustion bed decreases as the porosity increases [33]. Depending on whether or not a shrinking- and/or reacting-core mechanism is responsible for overall rate limiting, solids either decrease in density or particle size, each of which has its own kinetic parameter [34]. Knowledge of how the porosity and surface area changes as a function of temperature - and if the co-pyrolysis of biomass and coal can be represented by an additive model - could improve the accuracy and reliability of CFD models [35-37].

There is substantial discord among those who study the thermochemical conversion of blended fuels, specifically concerning the interactions - or lack thereof - between different solid fuels. The chemical analysis literature shows that different species are formed at different rates when fuels are blended than a simple additive nature indicates. Other studies that focus only on global reaction kinetics say that fuel blends are easily described by an additive or linear scheme, 
whereby each fuel contributes to the total activation energy or decomposition rate as a weighted fraction of its presence [38-42]. However, there is little data available in the literature that compares the porosity development in these blends. One of the few recent studies in this vein was performed by Rowan et al [43] on the co-pyrolysis of a 50-50 blend of coal and hardwood. The authors find some synergistic (or non-additive) tar and char yields, as well as FTIR char structures, for 50-50 blended streams. In this study we probe the porosities of pyrolyzed blends of a Pennsylvania Coal and Feed Corn Stover at different pyrolysis temperatures and three blend ratios (90-10, 80-20, 50-50 coal-biomass) to make inferences on the extent to which diffusion might limit thermal behavior due to changes in porosity. We look at the BET isotherms of the semi-carbonaceous chars resulting from the pyrolysis of these blends at multiple temperatures to determine the potential for waste-to-byproduct conversion such as concrete/cement additives and sorbent material. This is complemented by a nonisothermal thermogravimetric analysis of the coal-biomass blends to probe the reactivity of the fuel blends. This study compliments a recent publication from our laboratory [40] on the pyrolysis kinetics of blends of PA Coal and Feed Corn Stover determined via the distributed activation energy model.

\section{Materials \& Methods}

\subsection{Sample Preparation}

A commercial U.S. high-volatile bituminous coal from Pennsylvania was obtained as part of a shipment received by the PSNH Merrimack Station (Public Service of New Hampshire, now Eversource Energy) in October 2011. Feed corn stover was collected during the same time from the Coppal House Farm in Lee, NH. It was dried in a laboratory oven overnight to prevent decomposition. Table 1 supplies the proximate and ultimate analyses of each raw fuel used in this investigation. The higher heating values were measured in-house on a Parr Model 6100 Oxygen Bomb Calorimeter, standardized with NIST-traceable Benzoic acid. All samples were mechanically ground and sieved to a particle size of 125-250 $\mu \mathrm{m}$. van de Velden et al. [44] demonstrated that mass transfer limitations occur in the pyrolysis of large particles because of temperature gradients within the particle. As Gu et al. [45-47] have shown in their CFD models, 
the temperature gradients inside particles can be neglected with sufficiently small Biot numbers that would result from particles of this size and smaller.

The biomass and coal were blended at weight ratios of 90:10, 80:20, and 50:50, measured to the $0.1 \mathrm{mg}$ on a Sartorius semi-microbalance directly into clean glass vials. The samples were homogenized on a vortex mixter. The blended samples, along with raw samples of both coal and biomass, were pyrolyzed under high purity nitrogen gas with a flow rate of $125-150 \mathrm{~mL} / \mathrm{min}$ in a Thermo-Scientific Lindberg Blue TF55035A-1 tube furnace. They were heated at a rate of $10^{\circ} \mathrm{C} / \mathrm{min}$ and held at $110^{\circ} \mathrm{C}$ for 30 minutes to drive off moisture. They were then heated to their respective maximum temperatures of $300^{\circ} \mathrm{C}, 450^{\circ} \mathrm{C}, 600^{\circ} \mathrm{C}, 750^{\circ} \mathrm{C}$, and $900^{\circ} \mathrm{C}$ (at $10^{\circ} \mathrm{C} / \mathrm{min}$ ) and held for 30 minutes before being allowed to cool to room temperature under continuous nitrogen flow to prevent oxidation.

\subsection{Thermal Analysis}

To determine the volatile matter, fixed carbon, and ash content of each material, each pure solid fuel and blend was first pyrolyzed in a high purity nitrogen atmosphere (reactive plus protective gas flow at $70 \mathrm{~mL} / \mathrm{min}$ ) in a $70 \mu \mathrm{L}$ alumina crucible. Samples were heated to $110^{\circ} \mathrm{C}$ and held for 30 minutes to insure moisture removal. Then the sample was heated at $10^{\circ} \mathrm{C} / \mathrm{min}$ up to $910^{\circ} \mathrm{C}$ and held for 60 minutes in nitrogen to obtain a stable mass reading. The total amount of dry mass loss at this point was considered to be volatile matter. The gaseous atmosphere was changed to $50 \mathrm{~mL} / \mathrm{min}$ air (20 mL/min nitrogen balance protective flow) via an automatic flow controller as the temperature increased to $950^{\circ} \mathrm{C}$ at $10^{\circ} \mathrm{C} / \mathrm{min}$, and held for 30 minutes, to determine the percent of fixed carbon in the sample. (Percent ash was determined as the remaining matter after fixed carbon and volatile matter.) This analysis was performed in duplicate and the average values presented; despite the heterogeneity of the samples all pairs of measurements were within $5 \%$ of each other.

In addition to using the TGA to measure volatile and fixed matter, thermal analysis was used to gauge the reactivities of the varying fuel blends through derivative thermogravimetric curves of oxidation. As a solid fuel decomposes, it goes through a series of steps. Initially any water will leave the solid around $100-110^{\circ} \mathrm{C}$ (at atmospheric pressure), followed by devolatilizing, or 
pyrolysis, where the volatiles leave the solid matrix. These volatiles, if oxygen is present, will combust, followed by oxidation of the resulting char. The extent of mass conversion of a solid fuel at any time, $t, x(t)$, is determined from the TGA data as:

$$
x(t)=\frac{m_{0}-m_{t}}{m_{0}-m_{f}}
$$

where $m_{0}$ is initial mass, $m_{t}$ is mass at time $t$ in seconds, and $m_{f}$ is mass at complete decomposition. Derivative thermogravimetric curves, $\mathrm{dx}(\mathrm{t}) / \mathrm{dt}$ versus reaction temperature, are a convenient representation of the relative reactivity of each solid sample. From these curves we can see the peak reaction rates and temperatures; lower temperatures and higher rates indicate an overall higher reactivity. In this analysis of DTG curves, samples were heated under $50 \mathrm{~mL} / \mathrm{min}$ air $\left(20 \mathrm{~mL} / \mathrm{min}\right.$ nitrogen balance flow) to $110^{\circ} \mathrm{C}$ and held for 30 minutes, then heated at $100^{\circ} \mathrm{C} / \mathrm{min}$ up to $950^{\circ} \mathrm{C}$ and held for 30 minutes. Mass is logged every second to the $10^{-8}$ grams and temperature to the $0.01^{\circ} \mathrm{C}$.

\subsection{Surface Area and Porosity Analysis}

The surface area and porosity of the pyrolyzed coal, biomass and blends were analyzed on a Quantachrome Autosorb iQ gas sorption analyzer. The results were fitted to a multipoint BET curve to find total surface area with 11 points at a partial pressure of $\mathrm{P} / \mathrm{P}_{0}$ from 0.05 to 0.35 using nitrogen as the adsorptive gas. Samples pyrolyzed at $300^{\circ} \mathrm{C}, 600^{\circ} \mathrm{C}$, and $900^{\circ} \mathrm{C}$ were also subjected to a full adsorption-desorption analysis to determine pore volume, micropore surface area, and micropore volume using the Langmuir isotherm. We note there is some discord in the literature concerning the use of $\mathrm{N}_{2}$ versus $\mathrm{CO}_{2}$ for adsorption isotherms of solid fuels. Some argue that $\mathrm{CO}_{2}$ is preferential given potential diffusive limitations in small pores of $\mathrm{N}_{2}$ gas [48] whereas others insist that nitrogen is preferential given $\mathrm{CO}_{2}$ 's inability to fill larger microporosity [49], and that chars that have experienced some burnout are "better" characterized by nitrogen [50].

\section{Results \& Discussion}

One of the issues associated with co-firing of coal and biomass is fuel segregation that occurs due to the considerably higher reactivity (at lower temperatures) of biomass than coal during oxidation. This thermal mismatch is apparent in Figure 1, the derivative thermogravimetric (DTG) curves of the raw fuels and their blends oxidized at $100 \mathrm{~K} / \mathrm{min}$. Here we see how blends 
of coal and biomass demonstrate two distinct peak reactivities, the lower temperature peak showing higher mass loss rates as the percent biomass in the blend increases. The two fuels react at their characteristic temperatures. While there is some debate in the literature on varying degrees of synergy between co-fired fuels, the literature is in accord that such disparate fuels do display segregated oxidation. This segregation can be minimized or almost eliminated by carbonizing the biomass prior to co-firing, as demonstrated by Haykiri-Acma et al. [51]. Our current research probes the underlying thermal relationships between biomass and coal as they devolatilize in a fixed bed scenario. While most industrially relevant co-firing scenarios would occur in a fluidized reactor, these data provide insight into how the two fuels behave at varying temperatures in different proportions, shedding light into potential synergistic behavior between the solids, and exploring if there are certain temperature regimes that can be exploited in a pyrolysis scenario to minimize co-firing segregation issues. Also in Figure 1, we see a reasonably linear trend between the peak reaction temperature (for both peaks 1 and 2) and the percent biomass in a given blend. As the percent coal increases, the peak temperature increases and reaction rate decreases.

\subsection{Proximate Analysis}

If the blended fuel streams behave in an additive manner, we would expect that the volatile matter, fixed carbon and ash contents of the chars be a linear function of those resulting from pyrolysis of the pure fuels at each pyrolysis temperature. Table 2 presents the proximate analysis of the carbonized fuels and their blends as a function of pyrolysis temperature and blend composition. In Figure 2, we see that the volatile matter remaining from the blended fuels is lower than would be predicted by an additive scheme at each mass fraction biomass in blend, at every pyrolysis temperature. Interestingly, Rowan et al. [43] find, for the pyrolysis at $500^{\circ} \mathrm{C}$ of a 50-50 mixture of Pittsburgh \#8 coal and sawdust from Appalachian hardwoods, that the volatile matter content of the mixture was up to 3.8 to $7.7 \%$ lower than predicted by a weighted average of the two pure components; they suggest that this is evidence of a linear, or non-synergistic relationship. This conclusion is, they admit, somewhat tenuous, as though they find "linearity" in the proximate and ultimate analyses, FTIR data and char/tar mass yields suggest potential reaction synergism. For these reasons, in our study we probe several blend ratios, as well as pyrolysis temperatures. 
In Figure 2b, we find that the pure feed corn, as well as 50-50 blend, show a linear trend in terms of volatile matter content as a function of pyrolysis temperature. That is, as pyrolysis temperature increases for these two samples, the mass fraction of volatiles remaining in the solid decreases accordingly. For the coal, $90 \%$ and $80 \%$ coal blends, the volatile matter content is not linearly related to the pyrolysis temperature. This is not unexpected; coal begins to pyrolyze at considerably higher temperatures than biomass [52] and has an initial lower volatile content than the biomass. As can be seen in the figure, the pure coal and $90 \%$ coal blend loose less than $1 \%$ (certainly within the $95 \%$ confidence interval) volatile matter when pyrolyzed at $300^{\circ} \mathrm{C}$ for one hour.

\subsection{Porosity and Surface Area Development}

While thermal analyses (i.e. reaction kinetics studies) and bio-oil and pyrolysis gas analyses of blended biomass and coal fuel streams are replete in the literature, there is little work done on the chars resulting from co-pyrolysis, especially as a function of blend ratio and pyrolysis temperature. Table 2 shows the BET surface area (as a function of sample mass) and specific BET (surface area normalized to volatile matter) for each fuel and blend at the five pyrolysis temperatures. Figure 3 illustrates the surface area development as pyrolysis temperature increases. The solid lines in Figure 3 demonstrate what we might expect in terms of surface area development if the coal-biomass blends behaved as an "additive" function of mass fraction, $\mathrm{x}$, whereby the predicted surface area, $\mathrm{SA}_{\text {predict, }}$ would be equal to:

$\mathrm{SA}_{\text {predict }}=\mathrm{x}_{\mathrm{FC}} \mathrm{SA} \mathrm{FC}_{\mathrm{FC}}+\mathrm{x}_{\mathrm{IL}} \mathrm{SA}_{\mathrm{IL}}$

However, as Figure 3 shows, this is hardly the case. For all but the $50: 50$ blend at $450^{\circ} \mathrm{C}$, the "predicted" surface areas are considerably lower than the measured surface areas, suggesting that the coal and biomass synergistically interact to promote porosity development. We probe this further through Figure 4, which demonstrates the impact of pyrolysis temperature on the BET surface areas of each of the coal-feed corn blends. As pyrolysis temperature increases to $450^{\circ} \mathrm{C}$, the surface areas of the samples (with the exception of the 4:1 coal:corn sample) drop significantly, and then rise as the pyrolysis temperature reaches $600^{\circ} \mathrm{C}$. This is an expected phenomenon; at lower pyrolysis temperatures the evolved gases can re-condense to form tars and become trapped within the chars. The higher temperature is able to release them from the solid 
matrix [53-55]. The re-condensation of tars within solid biomass and coal matrices is welldocumented in the literature (for at least single samples), and here we have extended it to coalbiomass blends. While the degree of re-condensation within tars is quite variable, being dependent on pyrolysis unit design, residence time, and to some extent the specific biomass [5660]; overall, it has been shown that as pyrolysis temperature increases, the lower molecular weight (more volatile components) decrease, with a somewhat murkier picture for polycyclic aromatic hydrocarbons [61-63]. However, there is a balance between increasing pyrolysis temperature to prevent tar re-condensation, and removing the majority of the volatile compounds that promote high surface areas, as seen with higher pyrolysis temperatures. At $750^{\circ} \mathrm{C}$ and $900^{\circ} \mathrm{C}$ the BET surface areas of the coal chars, $5.246 \pm 0.142$ and $5.292 \pm 0.143 \mathrm{~m}^{2} / \mathrm{g}_{\text {char }}$, respectively, are considerably lower than the biomass and blends, which range from $11.149 \pm 0.301$ to $41.921 \pm 1.132 \mathrm{~m}^{2} / \mathrm{g}_{\text {char }}$, for the $9: 1$ pyrolyzed at $900^{\circ} \mathrm{C}$ and $1: 1$ at $750^{\circ} \mathrm{C}$ samples, respectively. At these higher temperatures, the volatiles likely exhaust themselves from the solid matrices; as it is these volatiles that provide much of the carbon responsible for surface area and porosity of the chars, their removal leads to a decrease in observed surface area.

From Figures 3 and 4, there is no generalizable "linear" or "additive" trend between the percent biomass in a blend and the BET surface area. Given prior literature indicating potential reaction synergies between coal-biomass blend pyrolysis, whereby different compounds evolve as a function of blend composition and temperature [14, 38 64-68], it is not surprising that such chemical synergies manifest in physical ways such as surface area. Surface area will generally reach a maximum at an intermediate burn-off temperature, specific to each fuel [69]; such behavior has been documented for not only oxidation, but also $\mathrm{CO}_{2}$ gasification [70-72], steam gasification[73,74 ] and hydrogenation [75], and now here for the devolatilization of coal, biomass, and their blends. In this case, the maximum surface area for the pure coal and $10 \mathrm{wt} \%$ biomass peaks around $600^{\circ} \mathrm{C}$, and for the 20 and $50 \mathrm{wt} \%$ biomass and pure biomass between 600 and $750^{\circ} \mathrm{C}$. The surface area decreases for all samples when the pyrolysis temperature reaches $900^{\circ} \mathrm{C}$

The synergistic behavior is less conclusive when we look at the development of microporosity detailed in Table 3. In Figure 5 we note that for the $300^{\circ} \mathrm{C}$ and $900^{\circ} \mathrm{C}$ blends, the is a fairly 
regular trend between the fraction of feed corn stover in the blend and both the micropore surface area and micropore volume. For these pyrolysis temperatures, as the percent biomass increases, the microporosity tends to increase; the effect is considerably more pronounced for $900^{\circ} \mathrm{C}$ pyrolysis than $300^{\circ} \mathrm{C}$. However, at $600^{\circ} \mathrm{C}$ we see a peak in both microporous surface area, and volume, for the 50:50 IL:FC blend. To compound this observation, Figure 5b shows the microporous volume fraction (micropore volume divided by total pore volume, as given in Table 3). For the pure coal, 10wt $\%$ biomass, 50:50 blend and pure corn stover (though only statistically significant for the 10 and $50 \mathrm{wt} \%$ blends), the $900^{\circ} \mathrm{C}$ pyrolyzed samples have the highest percent microporous surface areas; upwards of $45 \%$ for the 10 and $50 \mathrm{wt} \%$ blends. Interestingly, the $20 \mathrm{wt} \%$ blend pyrolyzed at $600^{\circ} \mathrm{C}$ has $44.3 \pm 4.0 \%$ microporosity, which is considerably higher than the $900^{\circ} \mathrm{C}$ pyrolyzed sample at $19.7 \pm 1.8 \%$ microporosity. The distribution of meso- and micropores within these solid fuels has potential consequences for the modeling of coal-biomass co-firing.

\subsection{Thermal Analysis}

Derivative thermogravimetric curves of oxidation at $100 \mathrm{~K} / \mathrm{min}$ of each solid fuel and blend, pyrolyzed at $300,450,600,750$ and $900^{\circ} \mathrm{C}$, are shown in Figure 6. In terms of overall reactivity, we point the reader to the scales of the y-axis in Figure 6. Figures 6a-d (pure coal and blends) have a $\mathrm{y}$-axis up to $0.005 \mathrm{~s}^{-1}$; the scale of the pure feed corn DTG plot is up to $0.012 \mathrm{~s}^{-1}$. As this suggests, the pure feed corn, even when pyrolyzed, is considerably more reactive than the coal and blends. This is due to the higher carbon contents and remaining volatile matter available in the pure biomasses, especially at the lower pyrolysis temperatures. As the percent of biomass increases in the blends, the reactivity clearly increases. This higher reactivity, coupled with remaining high carbon content - even for $\mathrm{FC}$ pyrolyzed at $900^{\circ} \mathrm{C}$ - suggests that the biochar remaining after pyrolysis (i.e. extraction of bio-oil and pyrolysis gas as fuels) could well be used as a co-fired fuel with coal. For all the pure fuels and blends, the samples pyrolyzed at 300 and $450^{\circ} \mathrm{C}$ are considerably more reactive - seen through both lower peak temperatures and higher peak reaction rates - than the samples pyrolyzed at $600^{\circ} \mathrm{C}$ and higher. Again this is attributed to the higher volatile matter content remaining in the solids fuels after pyrolysis at lower temperatures. Interestingly, for the 4-1 and 1-1 blends comprised of $450^{\circ} \mathrm{C}$ pyrolyzed biomass, there appears to be an increase in reactivity well beyond what might be expected for an additive 
scheme; the peak reaction rate of for these two blends is actually higher than the $300^{\circ} \mathrm{C}$ blend, (and for the 9-1 blend the $300^{\circ} \mathrm{C}$ and $450^{\circ} \mathrm{C}$ samples appear to have the same peak reaction rate). The peak reactivity of the PA coal pyrolyzed at $300^{\circ} \mathrm{C}$ is less than $0.003 \mathrm{~s}^{-1}$, and for the $450^{\circ} \mathrm{C}$ pyrolyzed sample is less than $0.002 \mathrm{~s}^{-1}$, yet the 9-1 blends pyrolyzed at these temperatures are both slightly above $0.003 \mathrm{~s}^{-1}$, and the 4-1 and 1-1 blends have peak reactivities over $0.003 \mathrm{~s}^{-1}$ for the $300^{\circ} \mathrm{C}$ pyrolyzed samples, and over $0.004 \mathrm{~s}^{-1}$ for the $450^{\circ} \mathrm{C}$ pyrolyzed samples. The peak reactivity for the pure FC pyrolyzed at these two temperatures is over $0.01 \mathrm{~s}^{-1}$. Therefore, it seems quite possible that the biomass is synergistically reacting with the coal to promote the rate of decomposition beyond the coal's inherent reactivity. Whether this is due to the pyrolyzed biomasses' reactivities, or other confounding factors such as mineral matter content of the biomass catalyzing the reactivity [76-78] is unknown at present, and warrants future investigation.

The DTG curves of oxidation at $100 \mathrm{~K} / \mathrm{min}$ of the pure fuels and blends pyrolyzed at each temperature demonstrate non-segregated fuels, especially as compared to those shown in Figure 1 for the raw fuels. Even for the samples pyrolyzed at $300^{\circ} \mathrm{C}$, there are single peaks for each fuel and blend, suggesting that the fuels are no longer segregating after this co-pyrolysis step. This has significant implications when it comes to utilizing biomass as a co-fired fuel. First, these results agree well with the recent study by Haykiri-Acma et al. [51] on the potential to improve co-firing by first carbonizing biomass, even at low temperatures. Second, our data suggest that the two fuels could be preheated - when comingled - at low temperatures to improve the overall firing step.

\subsection{Summation - with Qualitative Evidence}

The data presented here on the co-pyrolysis of feed corn stover and Pennsylvania Coal demonstrate several important thermal and physical characteristics that ought to be considered as transient properties when employing Computational Fluid Dynamics (CFD) models to co-fired fuel systems. From our proximate analyses, we find that the volatile matter content of pyrolyzed pure feed corn and the 50:50 blend is fairly linear with respect to temperature, though the 90 and $80 \mathrm{wt} \%$ coal blends loose considerably less than $1 \%$ at the lowest pyrolysis temperature and thus the trend is not quite linear for these materials. Conversely, this "additive" trend does not extend 
to surface area and porosity distributions in terms of composition or pyrolysis temperature.

Thermal analysis follows a general trend - that as the percent biomass in the blend increases, the reactivity increases (seen through higher reaction rates and lower peak reaction temperatures) and the same trend holds for pyrolysis temperature. Finally, Figure 7 shows SEM images of the pure fuels and blends pyrolyzed at $900^{\circ} \mathrm{C}$, at 2,000 and 10,000 magnifications (2K magnification scale bar $=2 \mu \mathrm{m}, 10 \mathrm{~K}$ mag $=1 \mu \mathrm{m}$ ). The feed corn stover shows a highly structured microporous material with amorphous nanoscale deposits along the surface. Conversely, the $900^{\circ} \mathrm{C}$ pyrolyzed coal shows amorphous, bulb-like formations along the surface of the char. From the proximate, thermal, surface area and qualitative analyses performed here, we see that the physical blending of biomass and coal results in changes to various physical characteristics of the fuel blend, depending on the percent of each solid present, and the pyrolysis profile.

\section{Conclusions}

In this investigation, we demonstrate the impact of blending ratio and pyrolysis temperature on the physical and thermal properties of feed corn stover and Pennsylvania coal blends. The overarching goals were (1) to provide information on the potential to model such blended fuel streams as additive functions of the blends' composition, versus the impact of any synergistic interactions between the blended fuels and (2) to explore the impact of pyrolysis temperature on this behavior on blended fuel streams. Overall, we find that these fuels are difficult to model using a simple additive scheme; the surface areas and microporosities of the blended streams are not a simple function of the materials present. Rather, it seems that the biomass and coal interact during pyrolysis; at low temperatures there is little impact of blend ratio on surface area and microporosity. However, as pyrolysis temperature increases, the presence of biomass in the blend considerably increases the degree of microporosity of the pyrolyzed fuel blend. Of import to combustion scenarios, fuel segregation, as noted through derivative thermogravimetric curves, seemingly disappears at pyrolysis temperatures as low as $300^{\circ} \mathrm{C}$. The evidence presented here suggests that CFD modeling of coal-biomass co-firing may be improved by including a dynamic term for porosity development as a function of both blend ratio and temperature. Further studies are recommended to develop such an algorithm that would enable prediction of such changes as a function of time and temperature in industrially relevant firing scenarios. The present work underscores that the co-firing of blended coal-biomass streams cannot be modeled using a simple 
additive scheme, but rather synergistic interactions between the two solid fuels suggest that the presence of biomass, with its greater reactivity and higher volatile content, may promote the devolatilization and development of porosity in blended fuel streams.

\section{Acknowledgements}

This material is based upon work supported by the National Science Foundation under Grant No. NSF CBET-1127774. The authors thank A. Patnaik for assistance with the SEM images. A. Vyas acknowledges the Boston University College of Engineering Summer Term Alumni Research Scholars (STARS) Program and the Boston University Undergraduate Research Program (UROP). T. Chellappa acknowledges the support of the CAPES Brazilian Post-Doctoral Fellowship Program.

\section{References}

1. Baxter, L. (2005). Biomass-coal co-combustion: opportunity for affordable renewable energy. Fuel, 84(10), 1295-1302.

2. Wang, C., Wang, F., Yang, Q., \& Liang, R. (2009). Thermogravimetric studies of the behavior of wheat straw with added coal during combustion. Biomass and Bioenergy, 33(1), 50-56.

3. Biagini, E., Lippi, F., Petarca, L., \& Tognotti, L. (2002). Devolatilization rate of biomasses and coal-biomass blends: an experimental investigation. Fuel, 81(8), 1041-1050.

4. De Jong, W., Di Nola, G., Venneker, B. C. H., Spliethoff, H., \& Wójtowicz, M. A. (2007). TGFTIR pyrolysis of coal and secondary biomass fuels: determination of pyrolysis kinetic parameters for main species and NO x precursors. Fuel, 86(15), 2367-2376.

5. Sami, M., Annamalai, K., \& Wooldridge, M. (2001). Co-firing of coal and biomass fuel blends. Progress in energy and combustion science, 27(2), 171-214.

6. Vamvuka, D., Kakaras, E., Kastanaki, E., \& Grammelis, P. (2003). Pyrolysis characteristics and kinetics of biomass residuals mixtures with lignite. Fuel, 82(15), 1949-1960.

7. Vamvuka, D., Pasadakis, N., Kastanaki, E., Grammelis, P., \& Kakaras, E. (2003). Kinetic modeling of coal/agricultural by-product blends. Energy \& fuels, 17(3), 549-558.

8. Guan, Y., Ma, Y., Zhang, K., Chen, H., Xu, G., Liu, W., \& Yang, Y. (2015). Co-pyrolysis behaviors of energy grass and lignite. Energy Conversion and Management, 93, 132-140.

9. Belošević, S. (2010). Modeling approaches to predict biomass co-firing with pulverized coal. Open Thermodynamics Journal, 4, 50-70.

10. Gayan, P., Adanez, J., Luis, F., García-Labiano, F., Cabanillas, A., Bahillo, A. \& Veijonen, K. (2004). Circulating fluidised bed co-combustion of coal and biomass. Fuel, 83(3), 277-286.

11. Porteiro, J., Collazo, J., Patiño, D., Granada, E., Moran Gonzalez, J. C., \& Míguez, J. L. (2009). Numerical modeling of a biomass pellet domestic boiler. Energy \& Fuels, 23(2), 1067-1075.

12. Bonelli, P. R., Buonomo, E. L., \& Cukierman, A. L. (2007). Pyrolysis of sugarcane bagasse and co-pyrolysis with an Argentinean subbituminous coal. Energy Sources, Part A, 29(8), 731-740.

13. Celaya, A. M., Lade, A. T., \& Goldfarb, J. L. (2015). Co-combustion of brewer's spent grains and Illinois No. 6 coal: Impact of blend ratio on pyrolysis and oxidation behavior. Fuel Processing Technology, 129, 39-51

14. Yangali, P., Celaya, A. M., \& Goldfarb, J. L. (2014). Co-pyrolysis reaction rates and activation energies of West Virginia coal and cherry pit blends. Journal of Analytical and Applied Pyrolysis, $108,203-211$. 
15. Abbassi, M. A., Grioui, N., Halouani, K., Zoulalian, A., \& Zeghmati, B. (2009). A practical approach for modelling and control of biomass pyrolysis pilot plant with heat recovery from combustion of pyrolysis products. Fuel Processing Technology, 90(10), 1278-1285.

16. Cooper, J., \& Hallett, W. L. H. (2000). A numerical model for packed-bed combustion of char particles. Chemical Engineering Science, 55(20), 4451-4460.

17. Gungor, A. (2013). Simulation of co-firing coal and biomass in circulating fluidized beds. Energy Conversion and Management, 65, 574-579.

18. Zhou, H., Jensen, A. D., Glarborg, P., Jensen, P. A., \& Kavaliauskas, A. (2005). Numerical modeling of straw combustion in a fixed bed. Fuel, 84(4), 389-403.

19. Shin, D., \& Choi, S. (2000). The combustion of simulated waste particles in a fixed bed. Combustion and flame, 121(1), 167-180.

20. Syred, N., Kurniawan, K., Griffiths, T., Gralton, T., \& Ray, R. (2007). Development of fragmentation models for solid fuel combustion and gasification as subroutines for inclusion in CFD codes. Fuel, 86(14), 2221-2231.

21. Yang, Y. B., Sharifi, V. N., \& Swithenbank, J. (2006). Substoichiometric conversion of biomass and solid wastes to energy in packed beds. AIChE journal, 52(2), 809-817.

22. Hermansson, S., \& Thunman, H. (2011). CFD modelling of bed shrinkage and channelling in fixed-bed combustion. Combustion and Flame, 158(5), 988-999.

23. Beeley, T., Crelling, Gibbins, J., R. Hurt, Lunden, M., Man, C., Williamson, J. \& Yang, N.Y.C. (1996) Transient high-temperature thermal deactivation of monomaceral-rich coal chars. In Twnenty-Sixth Symposium (International) on Combustion (Vol 26, No. 2, pp. 3103-3110). Elsevier.

24. Gómez-Barea, A., Ollero, P., \& Arjona, R. (2005). Reaction-diffusion model of TGA gasification experiments for estimating diffusional effects. Fuel, 84(12), 1695-1704.

25. Hu, S., Xiang, J., Sun, L., Xu, M., Qiu, J., \& Fu, P. (2008). Characterization of char from rapid pyrolysis of rice husk. Fuel processing technology, 89(11), 1096-1105.

26. Ryan, E. M., Tartakovsky, A. M., \& Amon, C. (2011). Pore-scale modeling of competitive adsorption in porous media. Journal of contaminant hydrology, 120, 56-78.

27. Storlie, C. B., Lane, W. A., Ryan, E. M., Gattiker, J. R., \& Higdon, D. M. (2015). Calibration of computational models with categorical parameters and correlated outputs via Bayesian smoothing spline ANOVA. Journal of the American Statistical Association, 110(509), 68-82.

28. Smith, I. (1982, December). The combustion rates of coal chars: a review. In Symposium (International) on combustion (Vol. 19, No. 1, pp. 1045-1065). Elsevier.

29. Peters, B. (2011). Validation of a numerical approach to model pyrolysis of biomass and assessment of kinetic data. Fuel, 90(6), 2301-2314.

30. Di Blasi, C. (1996). Heat, momentum and mass transport through a shrinking biomass particle exposed to thermal radiation. Chemical engineering science, 51(7), 1121-1132.

31. Yang, Y. B., Sharifi, V. N., Swithenbank, J., Ma, L., Darvell, L. I., Jones, J. M., \& Williams, A. (2007). Combustion of a single particle of biomass. Energy \& Fuels, 22(1), 306-316.

32. Pallarés, J., Arauzo, I., \& Williams, A. (2007). Integration of CFD codes and advanced combustion models for quantitative burnout determination. Fuel, 86(15), 2283-2290.

33. Gómez, M. A., Porteiro, J., Patiño, D., \& Miguez, J. L. (2014). CFD modelling of thermal conversion and packed bed compaction in biomass combustion. Fuel, 117, 716-732.

34. Peters, B. (1999). Classification of combustion regimes in a packed bed of particles based on the relevant time and length scales. Combustion and Flame, 116(1), 297-301.

35. Saastamoinen, J. J., Aho, M. J., \& Linna, V. L. (1993). Simultaneous pyrolysis and char combustion. Fuel, 72(5), 599-609.

36. Saastamoinen, J., \& Richard, J. R. (1996). Simultaneous drying and pyrolysis of solid fuel particles. Combustion and Flame, 106(3), 288-300.

37. Peters, B., \& Bruch, C. (2001). A flexible and stable numerical method for simulating the thermal decomposition of wood particles. Chemosphere, 42(5), 481-490. 
38. Aboyade, A. O., Görgens, J. F., Carrier, M., Meyer, E. L., \& Knoetze, J. H. (2013). Thermogravimetric study of the pyrolysis characteristics and kinetics of coal blends with corn and sugarcane residues. Fuel Processing Technology, 106, 310-320.

39. Agarwal, G., \& Lattimer, B. (2014). Physicochemical, kinetic and energetic investigation of coalbiomass mixture pyrolysis. Fuel Processing Technology, 124, 174-187.

40. Goldfarb, J. L., \& Ceylan, S. (2015). Second-generation sustainability: Application of the distributed activation energy model to the pyrolysis of locally sourced biomass-coal blends for use in co-firing scenarios. Fuel, 160, 297-308.

41. Jones, J. M., Kubacki, M., Kubica, K., Ross, A. B., \& Williams, A. (2005). Devolatilisation characteristics of coal and biomass blends. Journal of Analytical and Applied Pyrolysis, 74(1), 502-511.

42. Weiland, N. T., Means, N. C., \& Morreale, B. D. (2012). Product distributions from isothermal co-pyrolysis of coal and biomass. Fuel, 94, 563-570.

43. Rowan, S. L., Wu, F., Celik, I. B., \& Weiland, N. T. (2014). Experimental investigation of char generated from co-pyrolysis of coal and Appalachian hardwoods. Fuel Processing Technology, $128,354-358$.

44. Van de Velden, M., Baeyens, J., Brems, A., Janssens, B., \& Dewil, R. (2010). Fundamentals, kinetics and endothermicity of the biomass pyrolysis reaction. Renewable energy, 35(1), 232-242.

45. Papadikis K., Bridgwater A.V. \& Gu, S. (2008) CFD modelling of the fast pyrolysis of biomass in fluidised bed reactors, Part a: Eulerian computation of momentum transport in bubbling fluidised beds. Chem Eng Sci 63(16)4218-27.

46. Papadikis K., Gu, S. \& Bridgwater, A.V. (2009) CFD modelling of the fast pyrolysis of biomass in fluidised bed reactors. Part B: heat, momentum and mass transport in bubbling fluidised beds. Chem Eng Sci 64(5),1036-45.

47. Papadikis, K., Gu, S. \& Bridgwater, A.V. (2009) CFD modelling of the fast pyrolysis of biomass in fluidised bed reactors: modelling the impact of biomass shrinkage. Chem Eng J 149(1-3),41727.

48. Marsh, H., \& Wynne-Jones, W.F.K. (1964) The surface properties of carbon - I the effect of activated diffusion in the determination of surface area. Carbon 1(3), 267-279

49. Gregg, S.J. \& Sing K.S.W. (1982) Adsorption, Surface Area and Porosity. Academic Press, New York.

50. Rodríguez-Reinoso, F., A. Linares-Solano in Chemistry and Physics of Carbon, vol. 21. (1989) Thrower, P.A. Ed. Dekker, New York.

51. Haykiri-Acma, H., Yaman, S., \& Kucukbayrak, S. (2015). Does carbonization avoid segregation of biomass and lignite during co-firing? Thermal analysis study. Fuel Processing Technology, 137, 312-319.

52. Haykiri-Acma, H., \& Yaman, S. (2010). Interaction between biomass and different rank coals during co-pyrolysis. Renewable Energy, 35(1), 288-292.

53. Di Blasi, C. (1994). Numerical simulation of cellulose pyrolysis. Biomass and Bioenergy, 7(1), 87-98.

54. Quyn, D. M., Wu, H., Hayashi, J. I., \& Li, C. Z. (2003). Volatilisation and catalytic effects of alkali and alkaline earth metallic species during the pyrolysis and gasification of Victorian brown coal. Part IV. Catalytic effects of $\mathrm{NaCl}$ and ion-exchangeable $\mathrm{Na}$ in coal on char reactivity. Fuel, 82(5), 587-593.

55. Miguel, G. S., Fowler, G. D., \& Sollars, C. J. (1998). Pyrolysis of tire rubber: porosity and adsorption characteristics of the pyrolytic chars. Industrial \& engineering chemistry research, 37(6), 2430-2435.

56. Buss, W., Mašek, O., Graham, M., \& Wüst, D. (2015). Inherent organic compounds in biochartheir content, composition and potential toxic effects. Journal of environmental management, $156,150-157$. 
57. Buss, W., \& Mašek, O. (2014). Mobile organic compounds in biochar-a potential source of contamination-phytotoxic effects on cress seed (Lepidium sativum) germination. Journal of environmental management, 137, 111-119.

58. Cordella, M., Torri, C., Adamiano, A., Fabbri, D., Barontini, F., \& Cozzani, V. (2012). Bio-oils from biomass slow pyrolysis: A chemical and toxicological screening. Journal of hazardous materials, 231, 26-35.

59. Gundale, M. J., \& DeLuca, T. H. (2007). Charcoal effects on soil solution chemistry and growth of Koeleria macrantha in the ponderosa pine/Douglas-fir ecosystem. Biology and Fertility of Soils, 43(3), 303-311.

60. Spokas, K. A., Novak, J. M., Stewart, C. E., Cantrell, K. B., Uchimiya, M., DuSaire, M. G., \& Ro, K. S. (2011). Qualitative analysis of volatile organic compounds on biochar. Chemosphere, 85(5), 869-882.

61. Fagernäs, L., Kuoppala, E., \& Simell, P. (2012). Polycyclic aromatic hydrocarbons in birch wood slow pyrolysis products. Energy \& Fuels, 26(11), 6960-6970.

62. Fabbri, D., Rombolà, A. G., Torri, C., \& Spokas, K. A. (2013). Determination of polycyclic aromatic hydrocarbons in biochar and biochar amended soil. Journal of Analytical and Applied Pyrolysis, 103, 60-67.

63. Hale, S. E., Lehmann, J., Rutherford, D., Zimmerman, A. R., Bachmann, R. T., Shitumbanuma, V., O’Toole, A., Sundqvist, K.L., Arp H.P.H., \& Cornelissen, G. (2012). Quantifying the total and bioavailable polycyclic aromatic hydrocarbons and dioxins in biochars. Environmental science \& technology, 46(5), 2830-2838.

64. Krerkkaiwan, S., Fushimi, C., Tsutsumi, A., \& Kuchonthara, P. (2013). Synergetic effect during co-pyrolysis/gasification of biomass and sub-bituminous coal. Fuel Processing Technology, 115, 11-18.

65. Haykiri-Acma, H., \& Yaman, S. (2007). Synergy in devolatilization characteristics of lignite and hazelnut shell during co-pyrolysis. Fuel, 86(3), 373-380.

66. Ulloa, C. A., Gordon, A. L., \& García, X. A. (2009). Thermogravimetric study of interactions in the pyrolysis of blends of coal with radiata pine sawdust. Fuel Processing Technology, 90(4), 583-590.

67. Sonobe, T., Worasuwannarak, N., \& Pipatmanomai, S. (2008). Synergies in co-pyrolysis of Thai lignite and corncob. Fuel Processing Technology, 89(12), 1371-1378.

68. Park, D. K., Kim, S. D., Lee, S. H., \& Lee, J. G. (2010). Co-pyrolysis characteristics of sawdust and coal blend in TGA and a fixed bed reactor. Bioresource technology, 101(15), 6151-6156.

69. Aarna, I., \& Suuberg, E. M. (1998, December). Changes in reactive surface area and porosity during char oxidation. In Symposium (International) on Combustion (Vol. 27, No. 2, pp. 2933 2939). Elsevier.

70. Dutta, S., Wen, C. Y., \& Belt, R. J. (1977). Reactivity of coal and char. 1. In carbon dioxide atmosphere. Industrial \& Engineering Chemistry Process Design and Development, 16(1), 20-30.

71. Adschiri, T., \& Furusawa, T. (1986). Relation between CO 2-reactivity of coal char and BET surface area. Fuel, 65(7), 927-931.

72. Hurt, R. H., Sarofim, A. F., \& Longwell, J. P. (1991). The role of microporous surface area in the gasification of chars from a sub-bituminous coal. Fuel, 70(9), 1079-1082.

73. K.H. van Heek, H.-J. Mühlen J. Lahaye, P. Ehrburger (Eds.), (1991) Fundamental Issues in Control of Carbon Gasification Reactivity, Kluwer, Boston

74. Miura, K., Hashimoto, K., \& Silveston, P. L. (1989). Factors affecting the reactivity of coal chars during gasification, and indices representing reactivity. Fuel, 68(11), 1461-1475.

75. Cyprès, R., Planchon, D., \& Braekman-Danheux, C. (1985). Evolution of pore structure and active surface areas of coal and char during hydrogenation. Fuel, 64(10), 1375-1378.

76. Patwardhan, P. R., Satrio, J. A., Brown, R. C., \& Shanks, B. H. (2010). Influence of inorganic salts on the primary pyrolysis products of cellulose. Bioresource technology, 101(12), 4646-4655. 
77. Banks, S. W., Nowakowski, D. J., \& Bridgwater, A. V. (2016). Impact of potassium and phosphorus in biomass on the properties of fast pyrolysis bio-oil. Energy \& Fuels, 30(10), 80098018.

78. Dou, G., \& Goldfarb, J. L. (2017). In situ upgrading of pyrolysis biofuels by bentonite clay with simultaneous production of heterogeneous adsorbents for water treatment. Fuel, 195, 273-283.

79. NIST/SEMATECH e-Handbook of Statistical Methods, http://www.itl.nist.gov/div898/handbook/ accessed 7 August 2015. 


\section{Tables}

Table 1. Ultimate, proximate, and combustion enthalpy analyses of samples ${ }^{1,2}$

\begin{tabular}{|lcc|}
\hline $\begin{array}{c}\text { wt\% (Dry } \\
\text { Basis) }\end{array}$ & $\begin{array}{c}\text { Pennsylvania } \\
\text { Coal }\end{array}$ & $\begin{array}{c}\text { Feed Corn } \\
\text { Stover }\end{array}$ \\
\hline $\mathrm{C}$ & 76.28 & 46.55 \\
$\mathrm{H}$ & 5.33 & 5.66 \\
$\mathrm{~N}$ & 1.42 & 0.95 \\
$\mathrm{~S}$ & 1.73 & 0.13 \\
$\mathrm{O}$ & 7.65 & 39.59 \\
\hline Moisture & 6.55 & 4.54 \\
\hline Volatile & 32.18 & 75.77 \\
Fixed & 60.88 & 16.16 \\
Ash & 6.93 & 8.07 \\
\hline HHV $(\mathrm{MJ} / \mathrm{kg})$ & 30.93 & 11.60 \\
\hline
\end{tabular}

1. PA Coal Provided by PSNH Suppliers

2. Biomass Performed by Hazen Research, Golden, CO 
Table 2. Carbon contents and BET Surface area for coal, biomass and blends pyrolyzed at various temperatures between 300 and $900^{\circ} \mathrm{C}$ (with NIST-calculated standard deviations ${ }^{79}$ )

\begin{tabular}{|c|c|c|c|c|c|c|}
\hline & $\begin{array}{l}\text { Pyrolysis } \\
\text { Temperature, } \\
{ }^{\circ} \mathrm{C}\end{array}$ & $\begin{array}{l}\text { Volatile Matter, wt } \\
\text { frac }\end{array}$ & $\begin{array}{c}\text { Fixed Carbon, wt } \\
\text { frac }\end{array}$ & $\begin{array}{l}\text { Ash, (by } \\
\text { difference) } \\
\text { wt frac }\end{array}$ & $\begin{array}{l}\text { BET Surface Area, } \\
\mathrm{m}^{2} / \mathrm{g}\end{array}$ & $\begin{array}{l}\text { Specific Surface Area, } \\
\mathrm{m}^{2} / \mathrm{g}_{\mathrm{VM}}\end{array}$ \\
\hline \multirow{5}{*}{ 1:0 PA:FC } & 300 & $0.313 \pm 0.009$ & $0.610 \pm 0.018$ & 0.078 & $11.376 \pm 0.307$ & $36.403 \pm 0.983$ \\
\hline & 450 & $0.190 \pm 0.006$ & $0.719 \pm 0.022$ & 0.092 & $4.147 \pm 0.112$ & $21.859 \pm 0.590$ \\
\hline & 600 & $0.125 \pm 0.004$ & $0.771 \pm 0.023$ & 0.104 & $19.457 \pm 0.525$ & $156.215 \pm 4.218$ \\
\hline & 750 & $0.113 \pm 0.003$ & $0.722 \pm 0.022$ & 0.165 & $5.246 \pm 0.142$ & $46.588 \pm 1.258$ \\
\hline & 900 & $0.083 \pm 0.002$ & $0.802 \pm 0.024$ & 0.116 & $5.292 \pm 0.143$ & $63.885 \pm 1.725$ \\
\hline \multirow{5}{*}{ 9:1 PA:FC } & 300 & $0.365 \pm 0.011$ & $0.554 \pm 0.017$ & 0.081 & $17.236 \pm 0.465$ & $47.287 \pm 1.277$ \\
\hline & 450 & $0.216 \pm 0.006$ & $0.681 \pm 0.020$ & 0.103 & $8.719 \pm 0.235$ & $40.350 \pm 1.089$ \\
\hline & 600 & $0.129 \pm 0.004$ & $0.756 \pm 0.023$ & 0.115 & $33.014 \pm 0.891$ & $255.229 \pm 6.891$ \\
\hline & 750 & $0.106 \pm 0.003$ & $0.776 \pm 0.023$ & 0.118 & $14.226 \pm 0.384$ & $134.620 \pm 3.635$ \\
\hline & 900 & $0.106 \pm 0.003$ & $0.766 \pm 0.023$ & 0.128 & $11.149 \pm 0.301$ & $105.484 \pm 2.848$ \\
\hline \multirow{5}{*}{ 4:1 PA:FC } & 300 & $0.409 \pm 0.012$ & $0.478 \pm 0.014$ & 0.113 & $10.352 \pm 0.280$ & $25.307 \pm 0.683$ \\
\hline & 450 & $0.211 \pm 0.006$ & $0.667 \pm 0.020$ & 0.122 & $10.468 \pm 0.283$ & $49.687 \pm 1.342$ \\
\hline & 600 & $0.147 \pm 0.004$ & $0.712 \pm 0.021$ & 0.141 & $18.162 \pm 0.490$ & $123.340 \pm 3.330$ \\
\hline & 750 & $0.121 \pm 0.004$ & $0.751 \pm 0.023$ & 0.128 & $17.983 \pm 0.486$ & $148.713 \pm 4.015$ \\
\hline & 900 & $0.093 \pm 0.003$ & $0.773 \pm 0.023$ & 0.135 & $12.947 \pm 0.350$ & $139.772 \pm 3.774$ \\
\hline \multirow{5}{*}{ 1:1 PA:FC } & 300 & $0.417 \pm 0.013$ & $0.482 \pm 0.014$ & 0.101 & $27.174 \pm 0.734$ & $65.146 \pm 1.759$ \\
\hline & 450 & $0.339 \pm 0.010$ & $0.508 \pm 0.015$ & 0.154 & $5.247 \pm 0.142$ & $15.492 \pm 0.418$ \\
\hline & 600 & $0.184 \pm 0.006$ & $0.681 \pm 0.020$ & 0.135 & $40.319 \pm 1.089$ & $219.591 \pm 5.929$ \\
\hline & 750 & $0.171 \pm 0.005$ & $0.652 \pm 0.020$ & 0.177 & $41.921 \pm 1.132$ & $244.874 \pm 6.612$ \\
\hline & 900 & $0.097 \pm 0.003$ & $0.656 \pm 0.020$ & 0.246 & $18.255 \pm 0.493$ & $187.557 \pm 5.064$ \\
\hline \multirow{5}{*}{ 0:1 PA:FC } & 300 & $0.645 \pm 0.019$ & $0.156 \pm 0.005$ & 0.199 & $23.123 \pm 0.624$ & $35.847 \pm 0.968$ \\
\hline & 450 & $0.610 \pm 0.018$ & $0.110 \pm 0.003$ & 0.280 & $8.207 \pm 0.222$ & $13.454 \pm 0.363$ \\
\hline & 600 & $0.470 \pm 0.014$ & $0.173 \pm 0.005$ & 0.357 & $23.593 \pm 0.637$ & $50.163 \pm 1.354$ \\
\hline & 750 & $0.413 \pm 0.012$ & $0.122 \pm 0.004$ & 0.465 & $29.881 \pm 0.807$ & $72.421 \pm 1.955$ \\
\hline & 900 & $0.335 \pm 0.010$ & $0.206 \pm 0.006$ & 0.458 & $14.674 \pm 0.396$ & $43.750 \pm 1.181$ \\
\hline
\end{tabular}


Table 3. Micropore surface area, volume and total pore volume for full isotherms for coal, biomass and blends pyrolyzed at 300,600 and $900^{\circ} \mathrm{C}$ (with NIST-calculated standard deviations ${ }^{79}$ )

\begin{tabular}{|c|c|c|c|c|c|}
\hline & $\begin{array}{l}\text { Pyrolysis } \\
\text { Temperature, }{ }^{\circ} \mathrm{C}\end{array}$ & $\begin{array}{l}\text { Micropore Surface Area } \\
\left(\mathrm{m}^{2} / \mathrm{g}\right)\end{array}$ & Micropore volume $\left(\mathrm{cm}^{3} / \mathrm{g}\right)$ & Total Pore volume $\left(\mathrm{cm}^{3} / \mathrm{g}\right)$ & $\begin{array}{c}\text { Fraction Microporous } \\
\text { Volume }\end{array}$ \\
\hline \multirow{3}{*}{ 1:0 PA:FC } & 300 & $11.319 \pm 0.340$ & $4.00 \mathrm{E}-03 \pm 1.20 \mathrm{E}-04$ & $1.57 \mathrm{E}-02 \pm 4.70 \mathrm{E}-04$ & $0.255 \pm 0.023$ \\
\hline & 600 & $16.404 \pm 0.492$ & $6.00 \mathrm{E}-03 \pm 1.80 \mathrm{E}-04$ & $2.15 \mathrm{E}-02 \pm 6.46 \mathrm{E}-04$ & $0.279 \pm 0.025$ \\
\hline & 900 & $5.955 \pm 0.179$ & $2.00 \mathrm{E}-03 \pm 6.00 \mathrm{E}-05$ & $6.11 \mathrm{E}-03 \pm 1.83 \mathrm{E}-04$ & $0.328 \pm 0.029$ \\
\hline \multirow{3}{*}{ 9:1 PA:FC } & 300 & $15.674 \pm 0.470$ & $6.00 \mathrm{E}-03 \pm 1.80 \mathrm{E}-04$ & $2.44 \mathrm{E}-02 \pm 7.31 \mathrm{E}-04$ & $0.246 \pm 0.022$ \\
\hline & 600 & $15.011 \pm 0.450$ & $1.00 \mathrm{E}-02 \pm 3.00 \mathrm{E}-04$ & $3.60 \mathrm{E}-02 \pm 1.08 \mathrm{E}-03$ & $0.278 \pm 0.025$ \\
\hline & 900 & $12.264 \pm 0.368$ & $5.00 \mathrm{E}-03 \pm 1.50 \mathrm{E}-04$ & $1.03 \mathrm{E}-02 \pm 3.08 \mathrm{E}-04$ & $0.487 \pm 0.044$ \\
\hline \multirow{3}{*}{ 4:1 PA:FC } & 300 & $11.110 \pm 0.333$ & $4.00 \mathrm{E}-03 \pm 1.20 \mathrm{E}-04$ & $1.29 \mathrm{E}-02 \pm 3.86 \mathrm{E}-04$ & $0.311 \pm 0.028$ \\
\hline & 600 & $12.264 \pm 0.368$ & $6.00 \mathrm{E}-03 \pm 1.80 \mathrm{E}-04$ & $1.35 \mathrm{E}-02 \pm 4.06 \mathrm{E}-04$ & $0.443 \pm 0.040$ \\
\hline & 900 & $15.681 \pm 0.470$ & $4.00 \mathrm{E}-03 \pm 1.20 \mathrm{E}-04$ & $2.03 \mathrm{E}-02 \pm 6.09 \mathrm{E}-04$ & $0.197 \pm 0.018$ \\
\hline \multirow{3}{*}{ 1:1 PA:FC } & 300 & $19.899 \pm 0.597$ & $7.00 \mathrm{E}-03 \pm 2.10 \mathrm{E}-04$ & $2.93 \mathrm{E}-02 \pm 8.79 \mathrm{E}-04$ & $0.239 \pm 0.021$ \\
\hline & 600 & $58.998 \pm 1.770$ & $2.10 \mathrm{E}-02 \pm 6.30 \mathrm{E}-04$ & $3.60 \mathrm{E}-02 \pm 1.08 \mathrm{E}-03$ & $0.583 \pm 0.052$ \\
\hline & 900 & $25.405 \pm 0.762$ & $9.00 \mathrm{E}-03 \pm 2.70 \mathrm{E}-04$ & $1.74 \mathrm{E}-02 \pm 5.22 \mathrm{E}-04$ & $0.517 \pm 0.047$ \\
\hline \multirow{3}{*}{ 0:1 PA:FC } & 300 & $19.241 \pm 0.577$ & $7.00 \mathrm{E}-03 \pm 2.10 \mathrm{E}-04$ & $2.54 \mathrm{E}-02 \pm 7.62 \mathrm{E}-04$ & $0.276 \pm 0.025$ \\
\hline & 600 & $29.395 \pm 0.882$ & $1.00 \mathrm{E}-02 \pm 3.00 \mathrm{E}-04$ & $2.95 \mathrm{E}-02 \pm 8.85 \mathrm{E}-04$ & $0.339 \pm 0.031$ \\
\hline & 900 & $35.409 \pm 1.062$ & $1.30 \mathrm{E}-02 \pm 3.90 \mathrm{E}-04$ & $3.62 \mathrm{E}-02 \pm 1.09 \mathrm{E}-03$ & $0.359 \pm 0.032$ \\
\hline
\end{tabular}




\section{Figures for Publication}

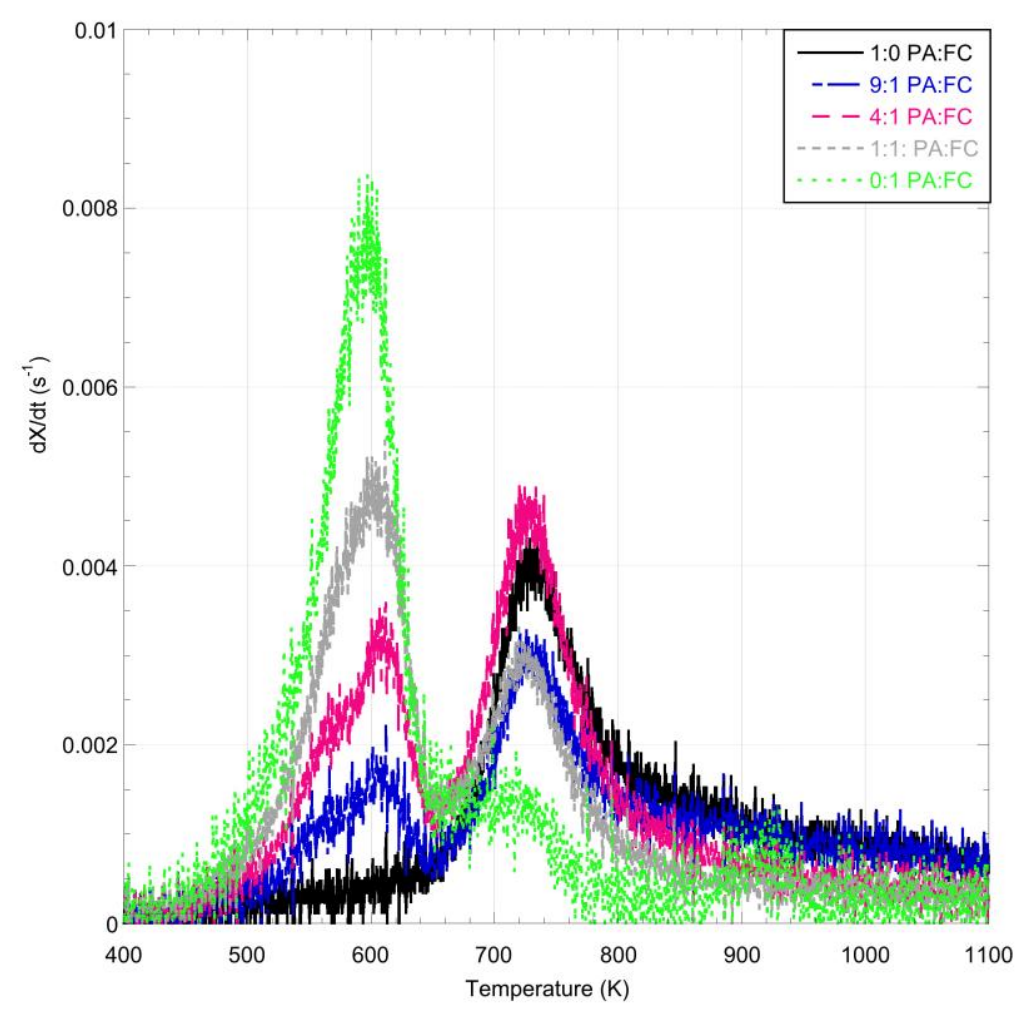

a. DTG curves

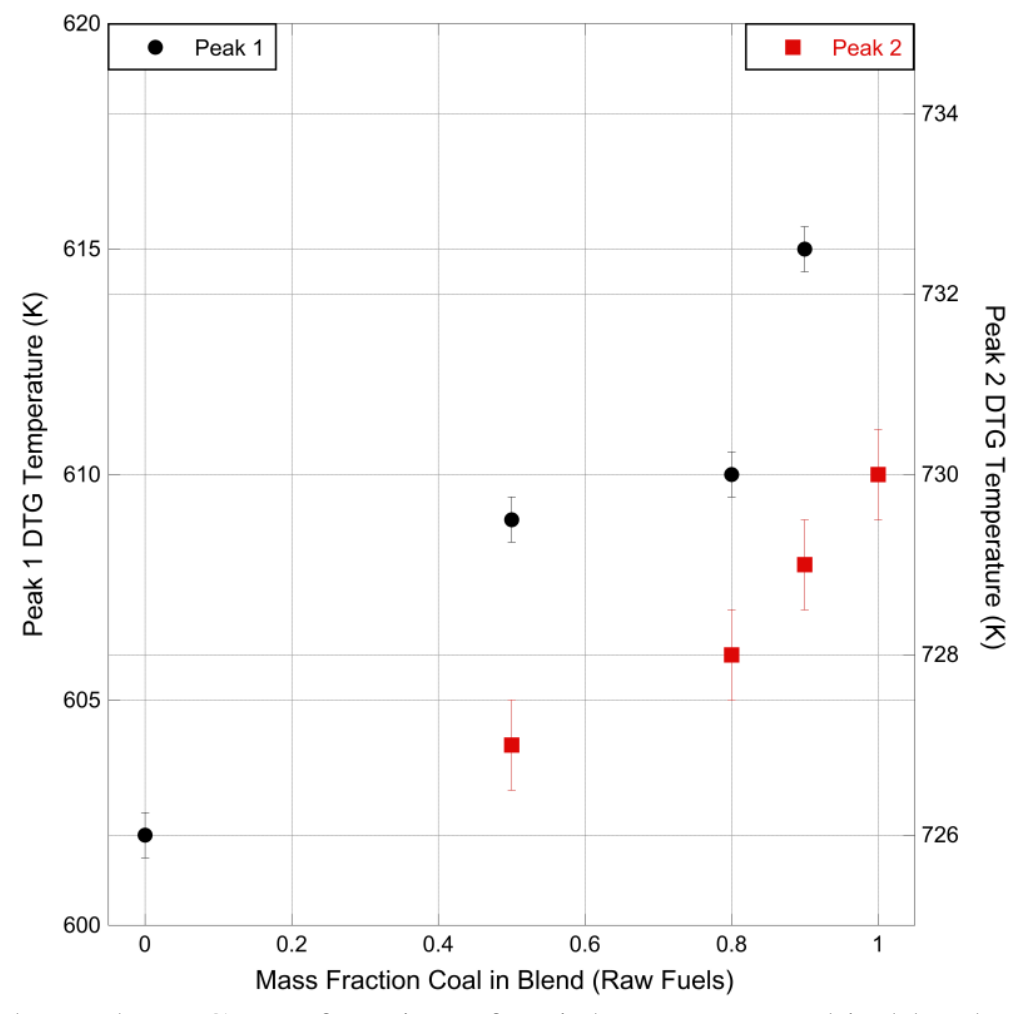

b. Peak DTG as a function of weight percent coal in blend

Figure 1. DTG analysis for oxidation at $100^{\circ} \mathrm{C} / \mathrm{min}$ for raw fuels and their blends 


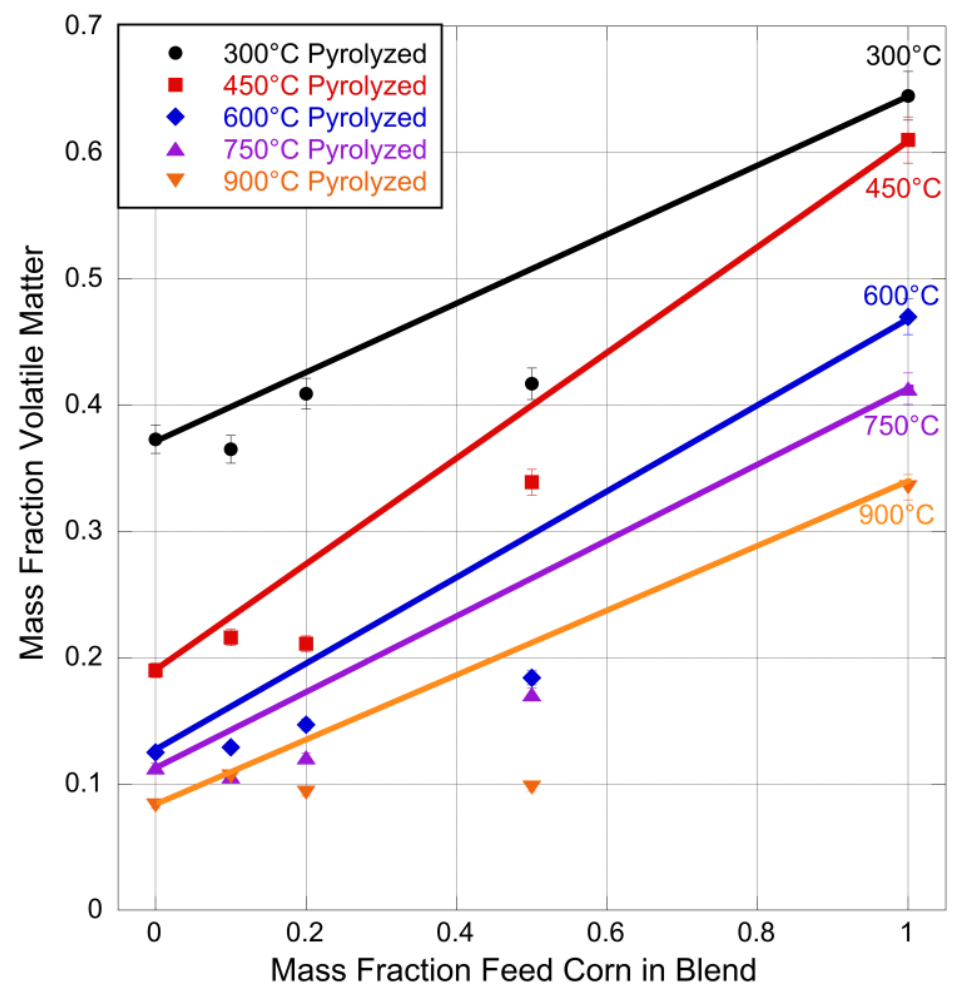

a. Mass fraction volatile matter as a function of fraction biomass in blend at each pyrolysis temperature; lines show "additive" relationship between solid fuels

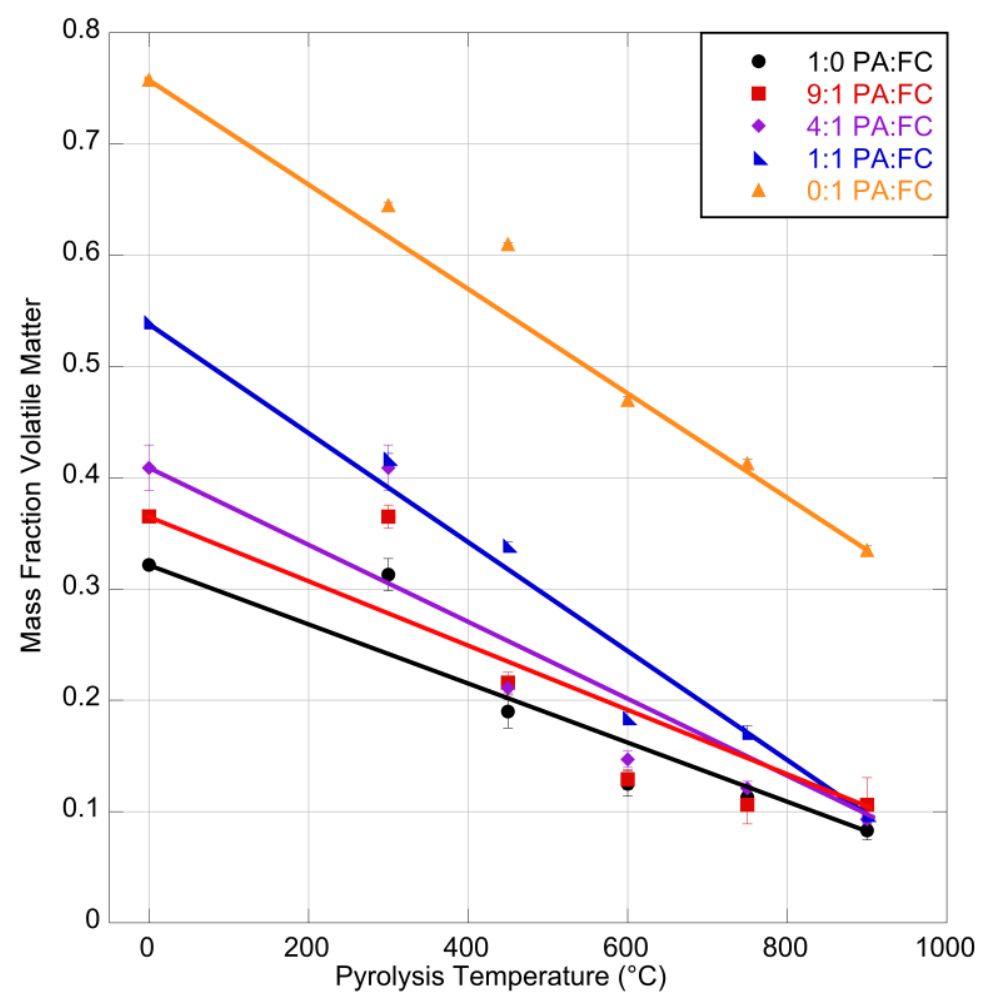

b. Mass fraction volatile matter as a function of pyrolysis temperature for each fuel and blend

Figure 2. Proximate analyses of pure fuels and blends (error bars indicate 95\% confidence interval) 


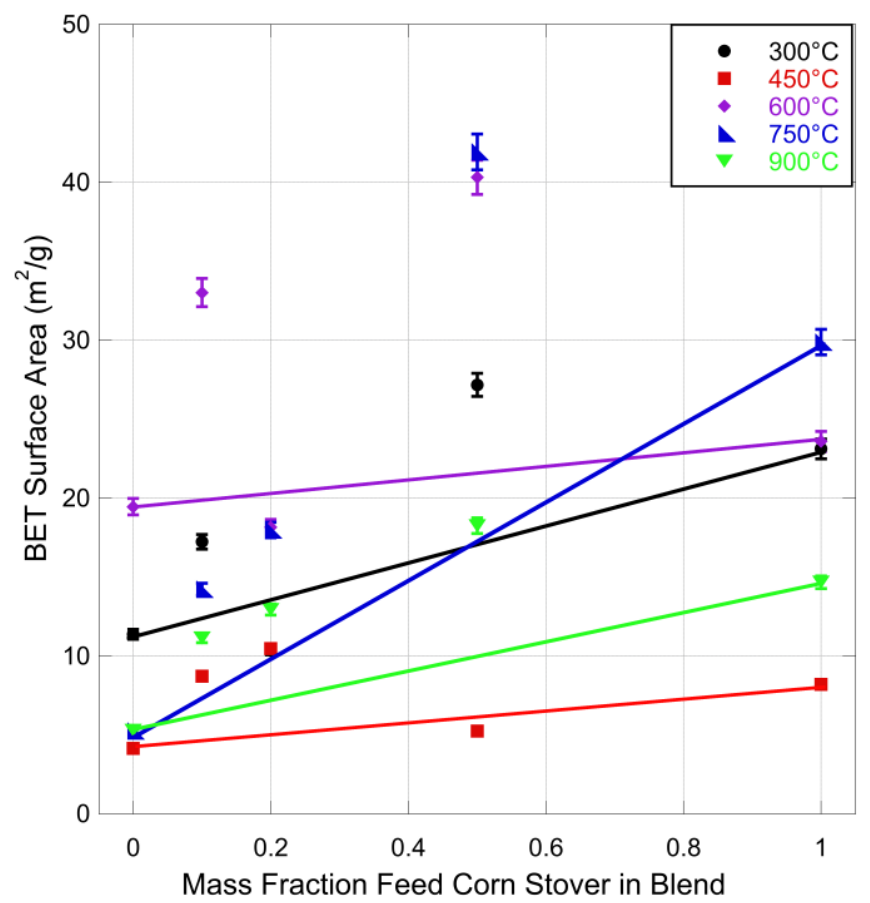

Figure 3. BET surface area as a function of mass fraction biomass in blend at each pyrolysis temperature with solid lines showing "additive" predicted behavior for surface area as a function of composition (error bars indicate $95 \%$ confidence interval)

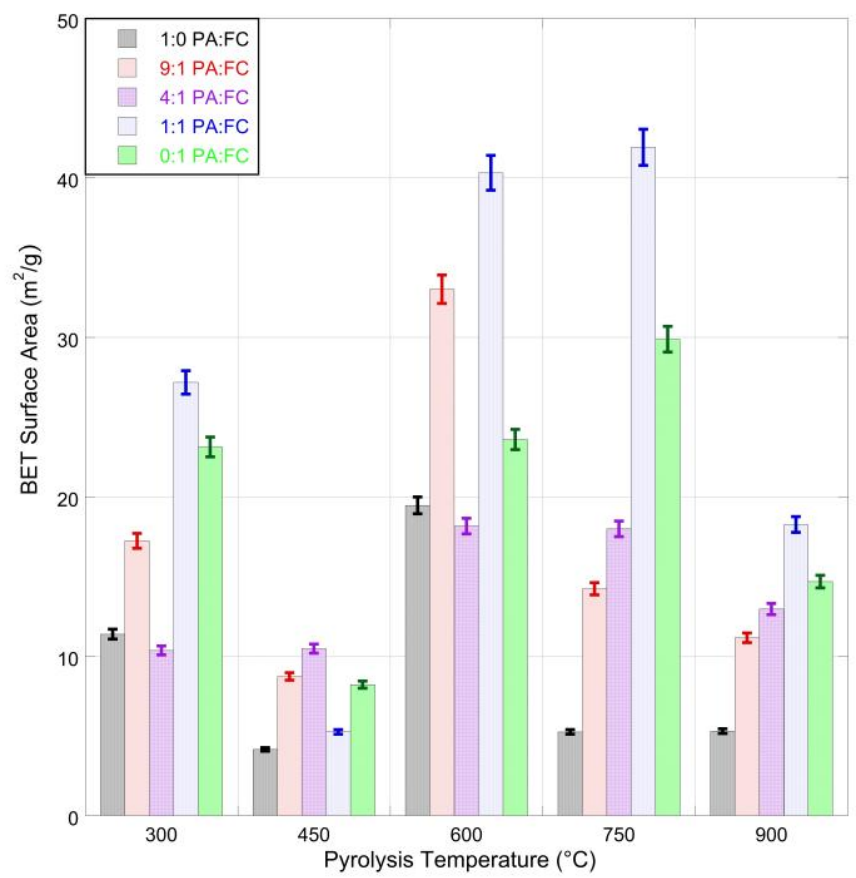

Figure 4. BET Surface area as a function of pyrolysis temperature for each blend (error bars indicate $95 \%$ confidence interval) 


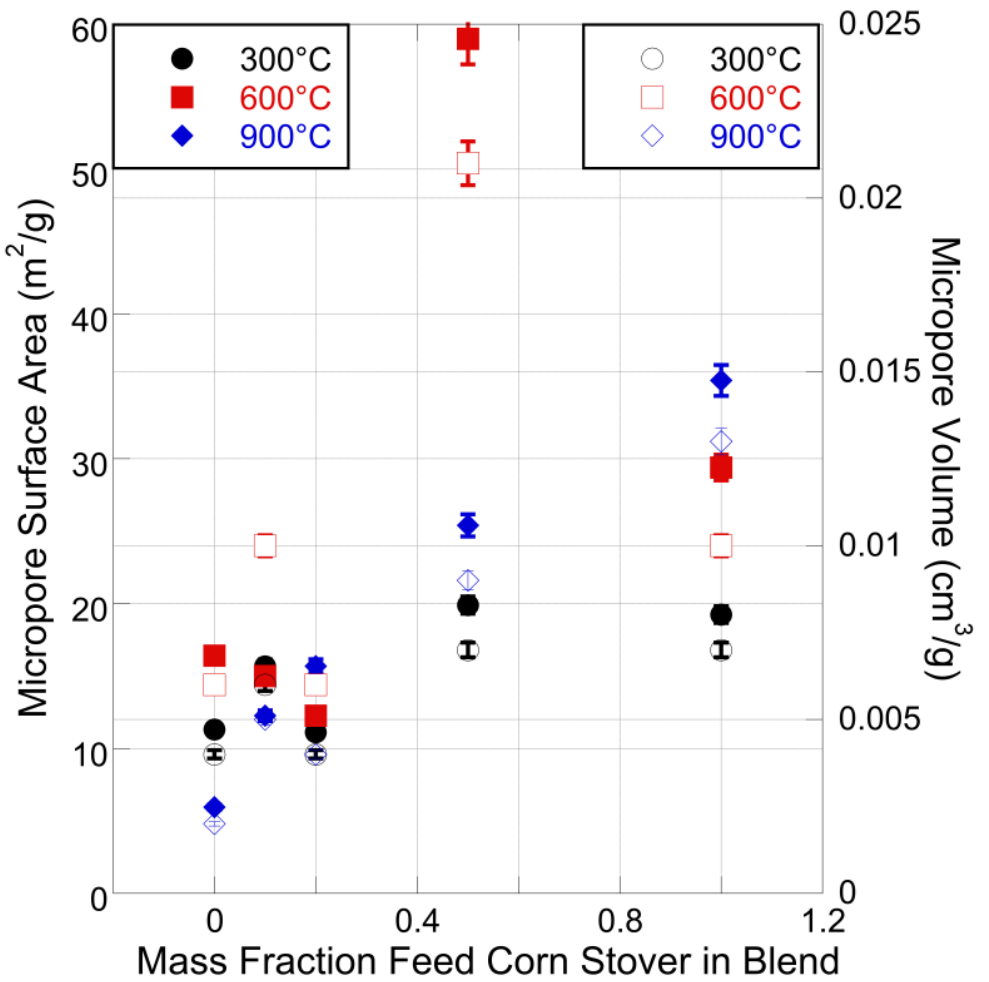

a. Micropore surface area and volume

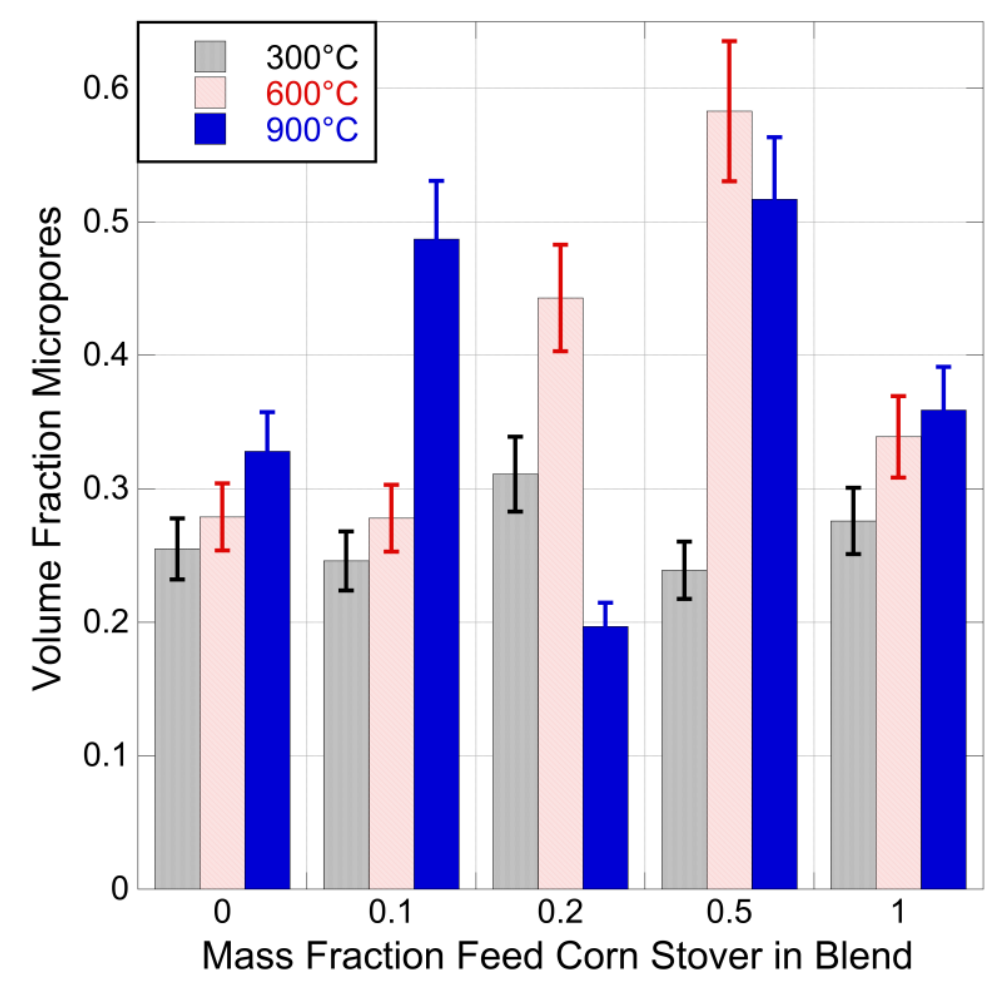

b. Fraction of microporosity comprising total pore volume

Figure 5. Development of microporosity of IL coal, feed corn stover and blends as a function of pyrolysis temperature and mass fraction feed corn stover in blend (error bars indicate $95 \%$ confidence interval) 


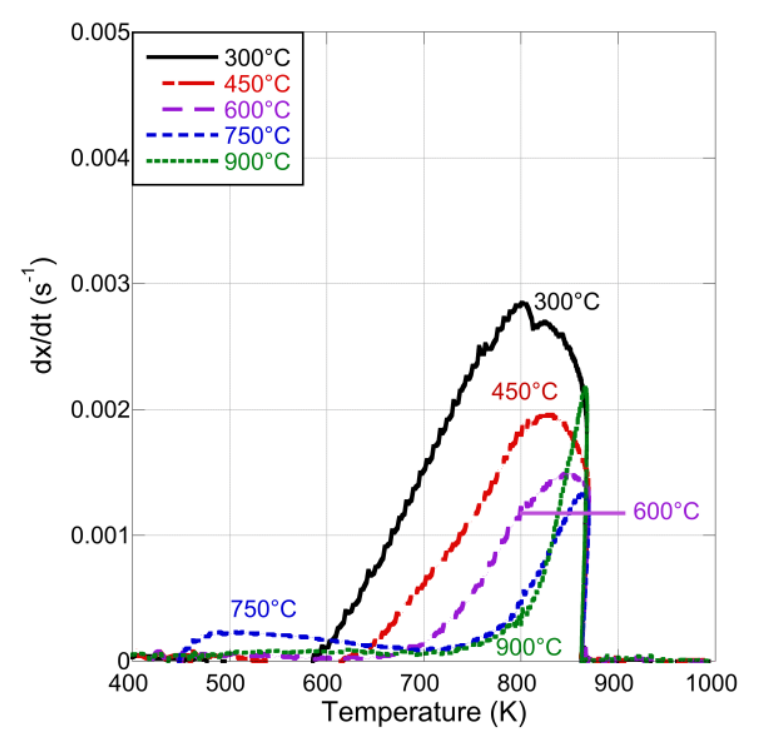

a. 1-0 PA:FC

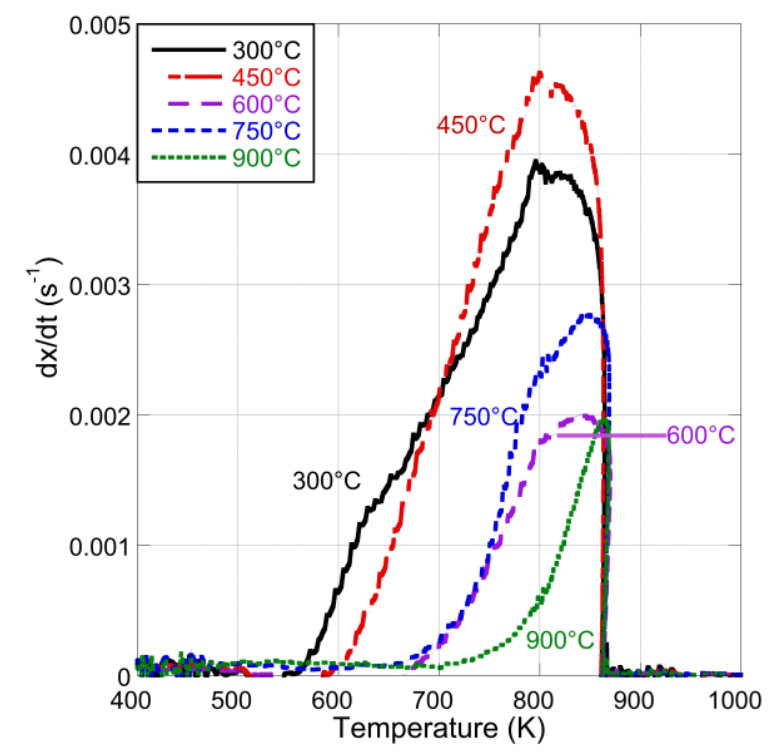

d. 1-1 PA:FC

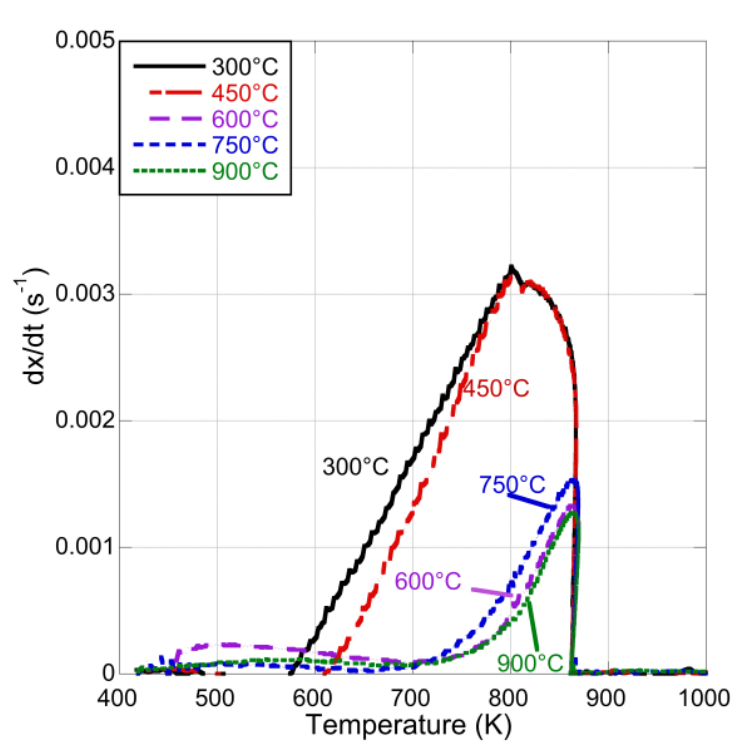

b. 9-1 PA:FC

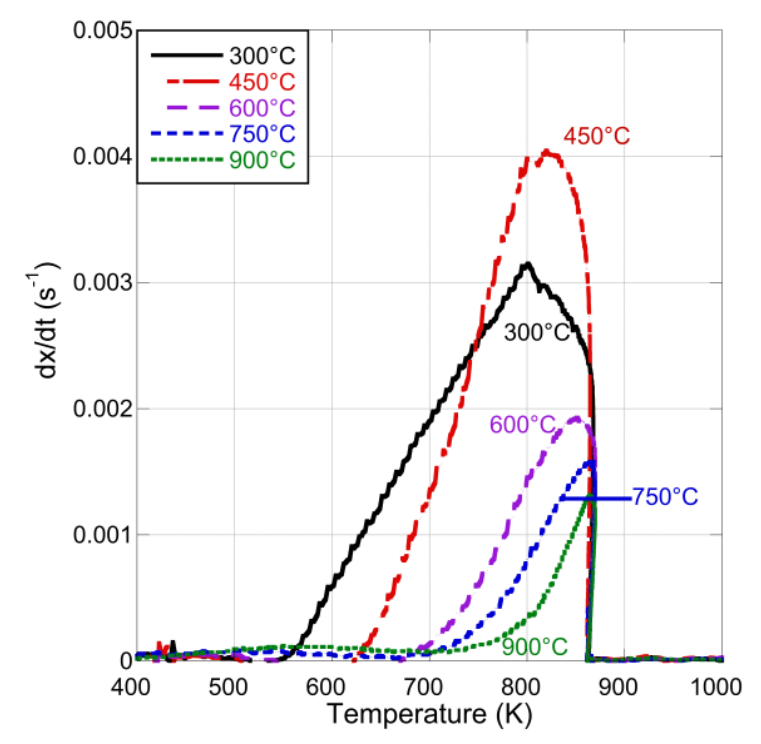

c. 4-1 PA:FC

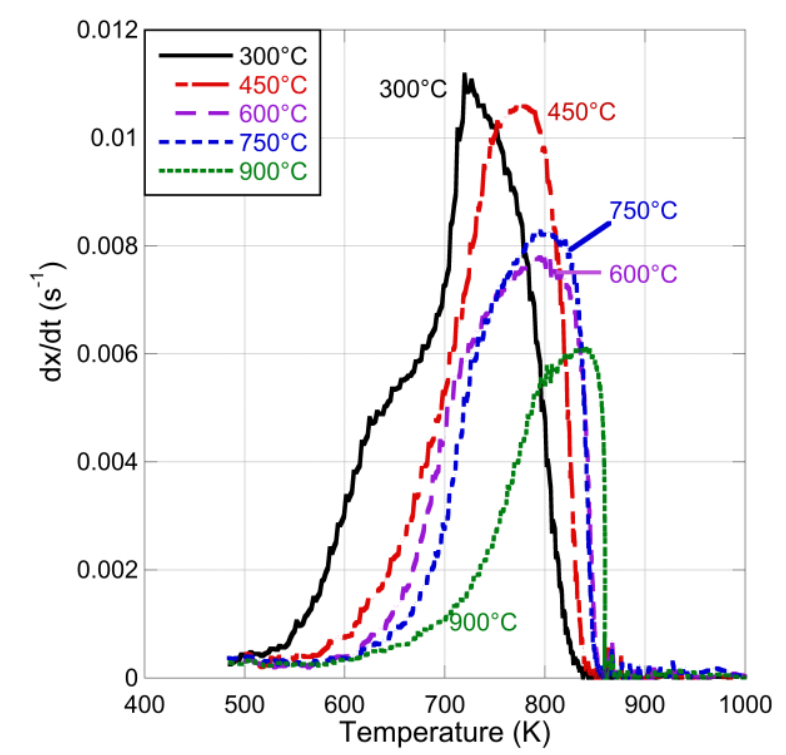

e. 0-1 PA:FC

Figure 6. DTG curves for the oxidation, at 100K/min, of pyrolyzed solid fuels and their blends 


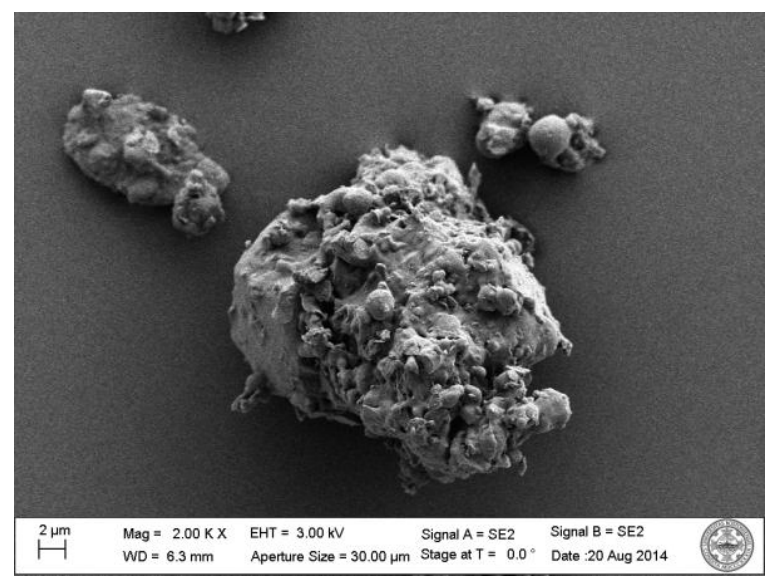

a. PA Coal, 2K Mag

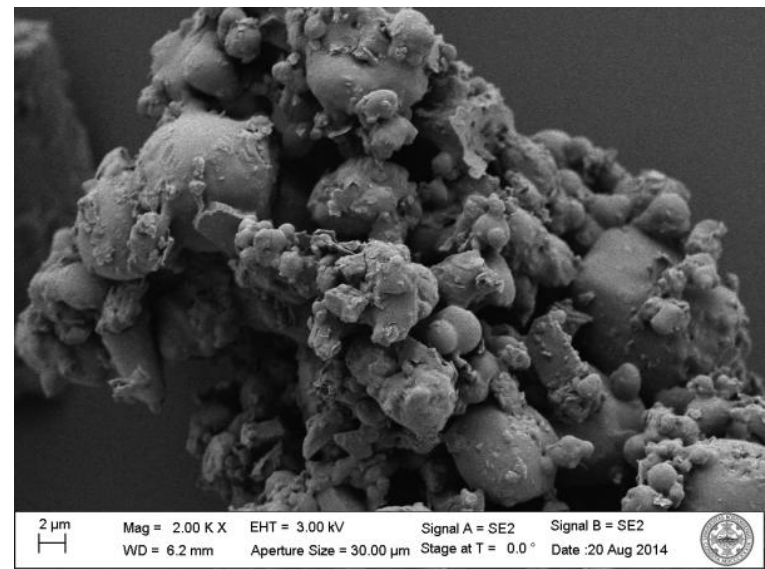

c. 9:1 PA:FC, 2K Mag

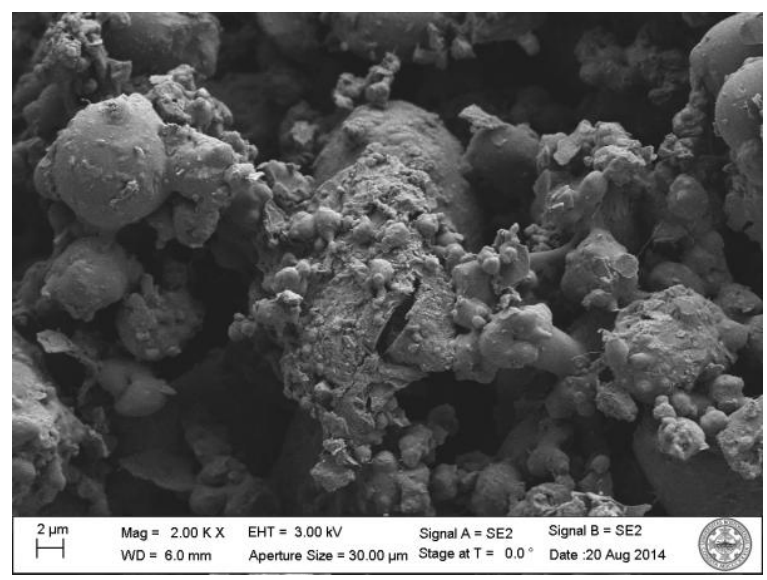

e. 4:1 PA:FC, 2K Mag

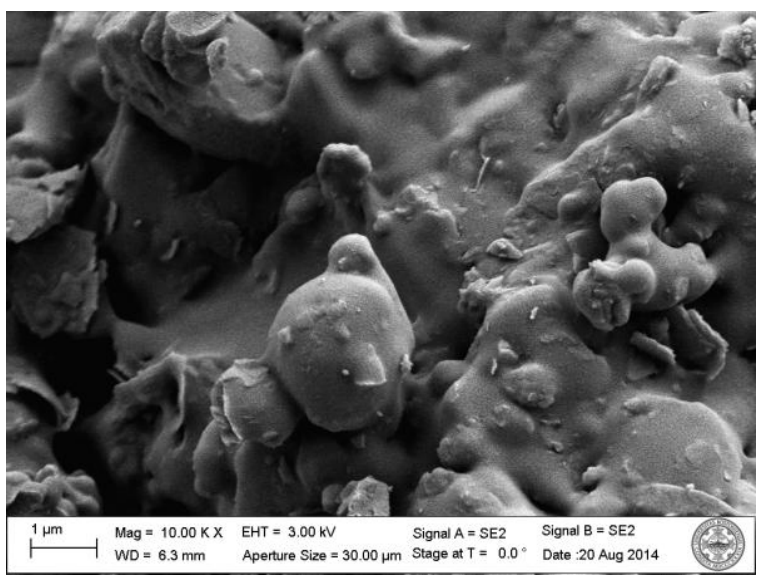

b. PA Coal, 10K Mag

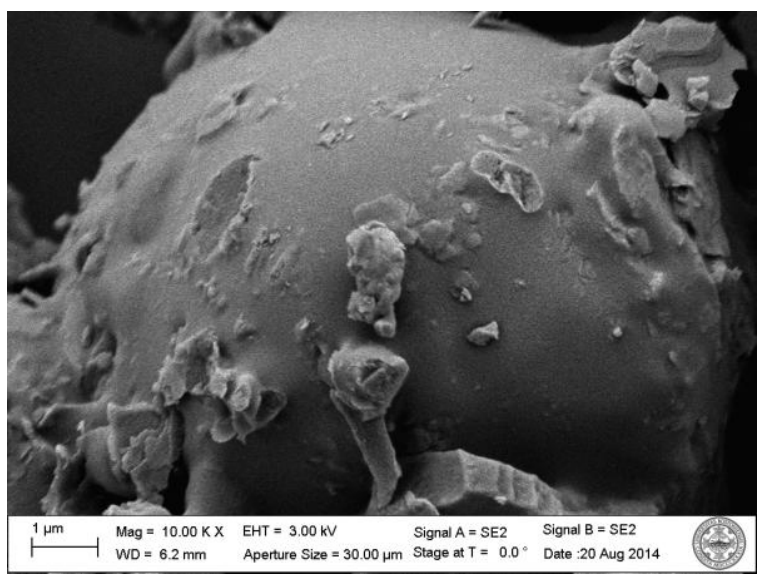

d. 9:1 PA:FC, 10K Mag

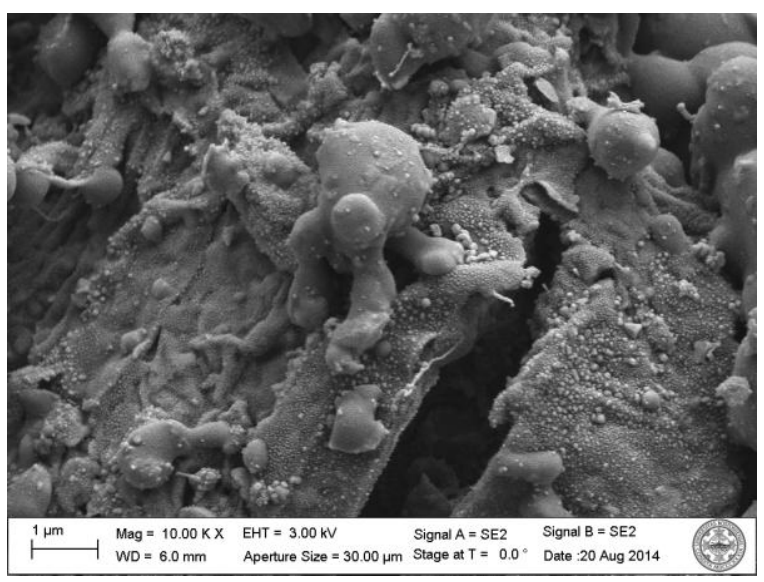

f. 4:1 PA:FC, 10K Mag 


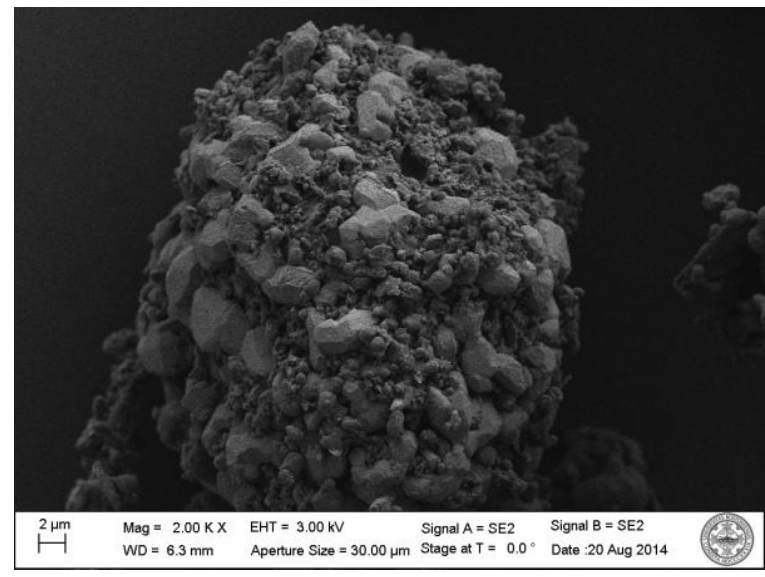

g. 1:1 PA:FC, 2K Mag

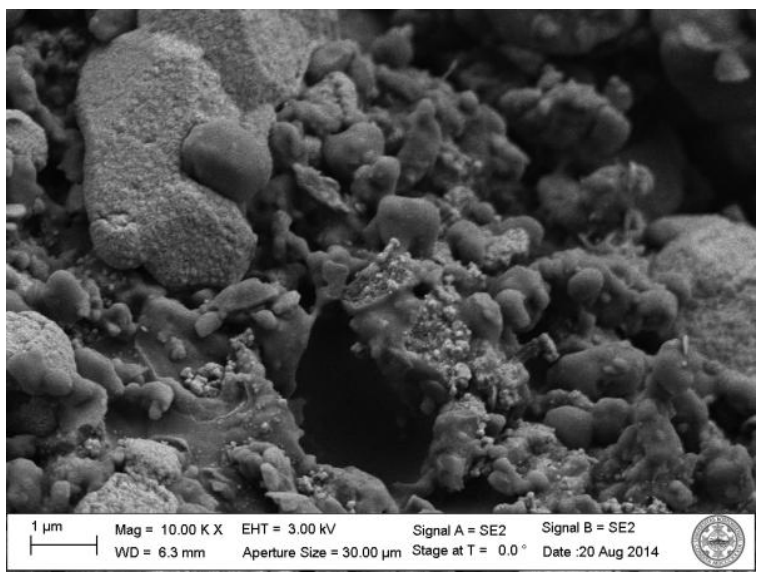

h. 1:1 PA:FC, 10K Mag
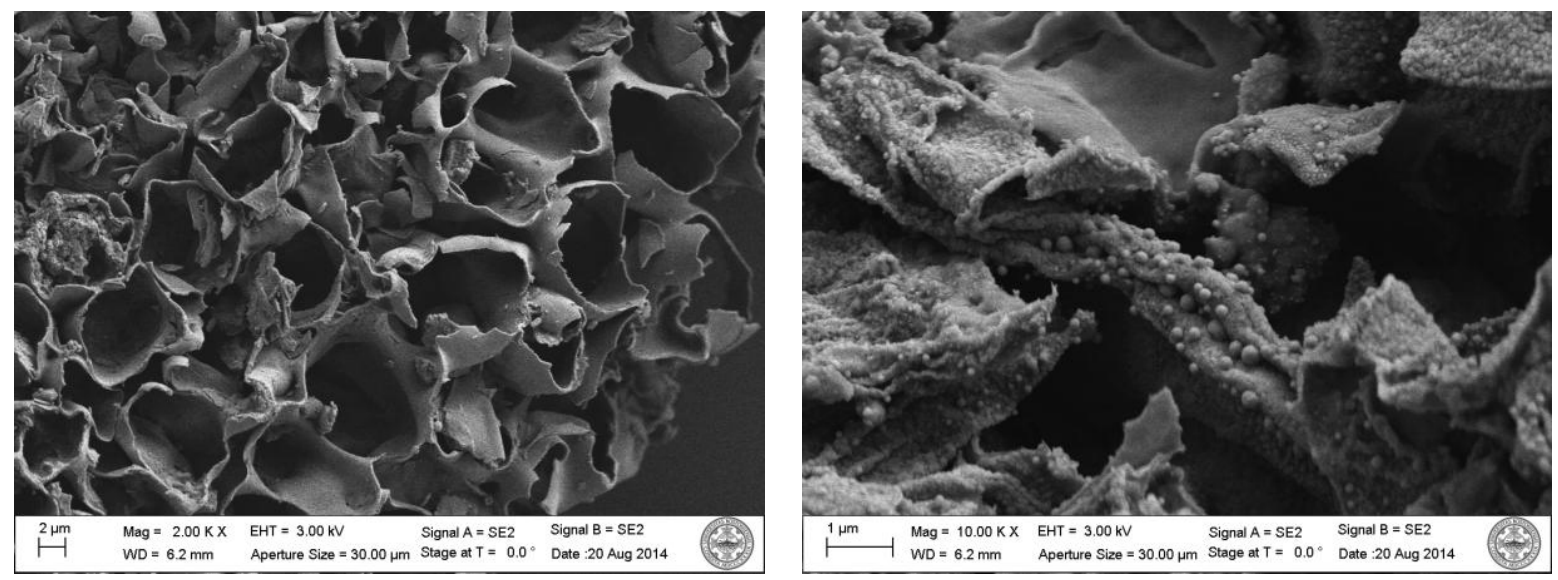

i. Feed Corn, 2K Mag

j. Feed Corn, 10K Mag

Figure 7. SEM images at 2 and $10 \mathrm{~K}$ magnification for PA Coal, Feed Corn Stover, and blends pyrolyzed at $900^{\circ} \mathrm{C}$ 